CRADA BNL-C-96-01

\title{
RAPTOR GAS GUN TESTING EXPERIMENT
}

\author{
Prepared by \\ Gaby Ciccarelli, Mano Subudhi, and Robert Hall \\ Department of Advanced Technology \\ Brookhaven National Laboratory \\ Upton, NY 11733 \\ RECEIVED \\ Prepared for $\quad$ SEP 071999 \\ Brooklyn Union \\ OSTI \\ Consolidated Edison \\ Gas Research Institute
}

June 12, 1998 


\section{DISCLAIMER}

This report was prepared as an account of work sponsored by an agency of the United States Government. Neither the United States Government nor any agency thereof, nor any of their employees, make any warranty, express or implied, or assumes any legal liability or responsibility for the accuracy, completeness, or usefulness of any information, apparatus, product, or process disclosed, or represents that its use would not infringe privately owned rights. Reference herein to any specific commercial product, process, or service by trade name, trademark, manufacturer, or otherwise does not necessarily constitute or imply its endorsement, recommendation, or favoring by the United States Government or any agency thereof. The views and opinions of authors expressed herein do not necessarily state or reflect those of the United States Government or any agency thereof. 


\section{DISCLAIMER}

Portions of this document may be illegible in electronic image products. Images are produced from the best available original document. 
CRADA BNL-C-96-01

\section{CONTENTS}

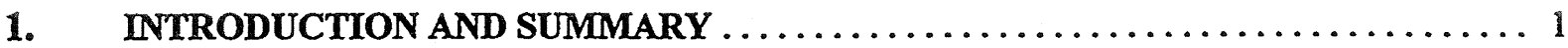

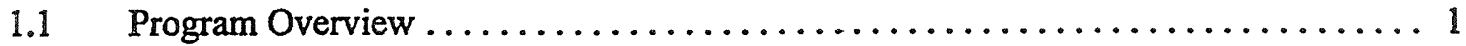

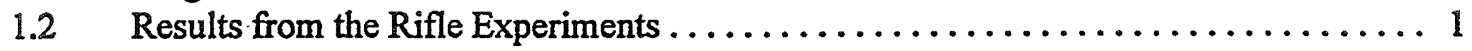

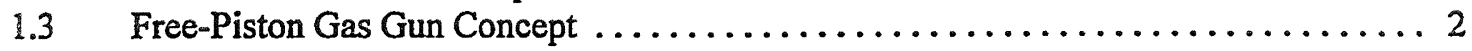

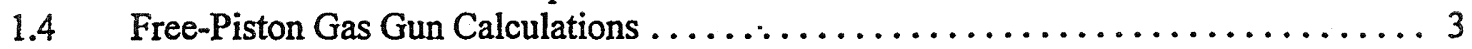

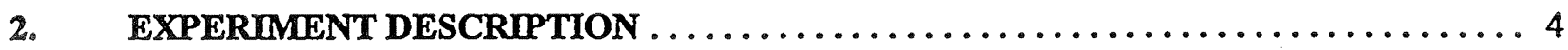

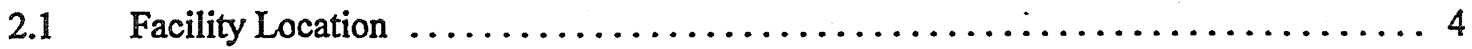

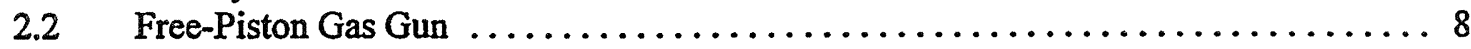

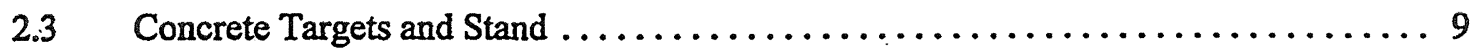

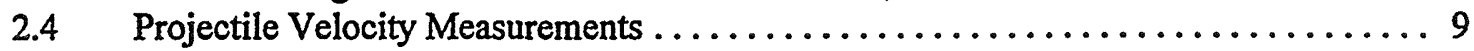

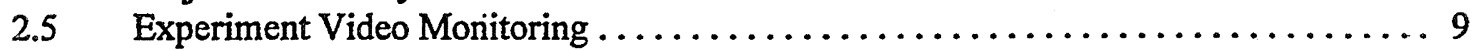

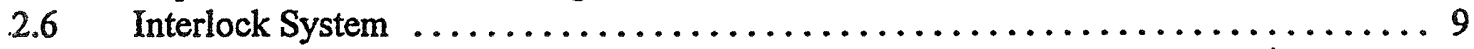

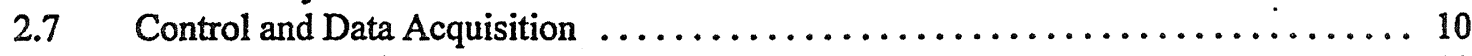

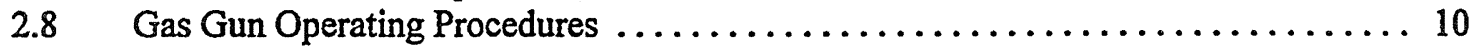

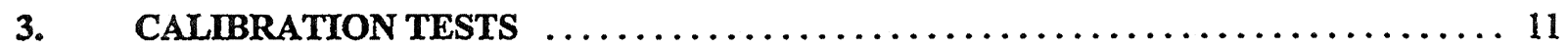

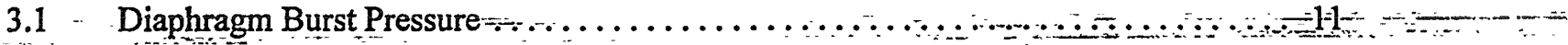

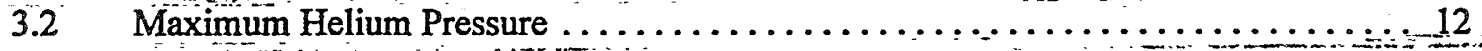

-3:3 Projectile Velocity

4. CONCRETE TARGET IMPACT TESTS $\ldots \ldots \ldots \ldots \ldots \ldots \ldots \ldots \ldots \ldots \ldots \ldots \ldots$

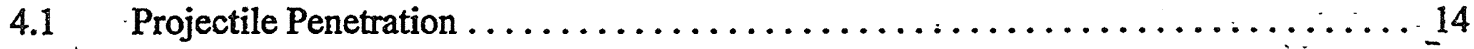

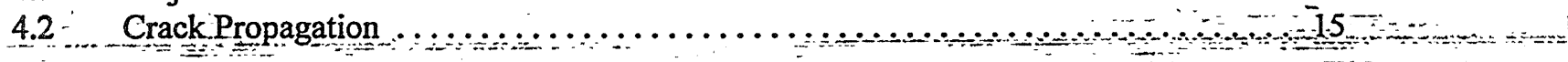

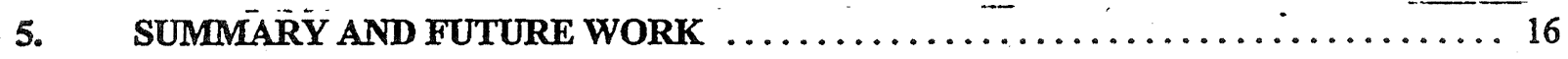

APPENDIX A

Numerical Code for the Design of a Free Piston Gas Gun 


\section{LIST OF FIGURES}

Fig. No.

1. Photograph of the rifle test apparatus

2. Schematic showing various applications of a Free-Piston Compressor

3a. Predicted piston velocity versus distance from diaphragm location

3b. Predicted helium pressure versus time from piston release

4a. Predicted piston velocity versus time from piston release just before diaphragm rupture

4b. Predicted helium pressure versus time from piston release just before diaphragm rupture

5a. Predicted projectile velocity versus distance from diaphragm

5b. Predicted projectile velocity versus time from piston release

6. Schematic showing an overview of the NBTF surroundings

7. Schematic showing an overview of the Experimental Hall

8. Schematic of the experimental room layout

9. Schematic of the RAPTOR gas gun and associated gas handling system

10. Photographs of the RAPTOR gas gun and gas handling system

11. Photographs of the two different projectiles and sabot used in the gas gun

12. - Photograph of the target stand with concrete target in place

13. - Helium pressure-time history with the compression tube end closed

14. Peak helium pressure versus initial helium pressure

15. Helium pressure-time history measured at locations before and after diaphragm

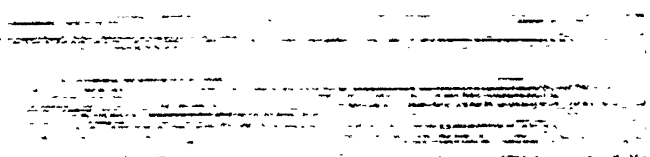

16. Helium pressure-time history measured at locations before and after diaphragm

17. Measured projectile velocity versus -initial helium pressure with 500 psi air

18. Measured projectile velocity versus initial helium pressure with $750 \mathrm{psi}$ air

19. Schematic of concrete targets showing impact locations and run numbers

20. Schematic of concrete targets showing impact locations and penetration depths in inches

21. Photograph of cracked 4" thick concrete target, test series \#70-74 of Figure 19

22. Photograph of completely broken up 4 "thick concrete target 
CRADA BNL-C-96-01

\section{RAPTOR GAS GUN TESTING EXPERIMENT}

\section{INTRODUCTION}

\subsection{Program Overview}

The present industry wide method for cutting and repairing sections of concrete pavements using jack hammers is slow, noisy, and labor intensive. These devices are very heavy and are manually operated, as a result, their use can result in adverse health hazards to personnel (e.g., back injuries). The jackhammer has been in use for many decades, with very little improvement. The gas industry is in need of a faster; quieter, cleaner method of sectioning concrete pavements in city streets in order to gain access to underground pipelines. This report provides a summary of the work done by BNL's Department of Advanced Technology under contract with the Gas Research Institute, Consolidated Edison Company of New York and Brooklyn Union to develop such a technology.

The method and device proposed here to breakup concrete pavement represents a completely revolutionary approach with no competing technology. The BNL approach for breaking up concrete pavement is by the impact of multiple high-speed gram-sized steel projectiles. The BNL launching device, here-on-in referred to as RAPTOR (acronym for Rapid Cutter of Concrete) consists of a free-piston gas gun designed to launch projectiles at various velocities. The projectile impact on the concrete surface results in local surface cratering and projectilepenetration. If the spacing between projectile impact points is close enough, global damage to the pavement is incurred in the form of crack propagation from impact point to impact point. By repeated or simultaneous, launching of multiple projectiles at a predetermined spacing, the concrete pavementcan be broken up into small chunks of concrete, similar to the final results of a jackhammer, and then carted away using conventional methods. Clearly the projectile impact point spacing required for crack propagation is governed by many parameters, including the projectile momentum and the pavement thickness.
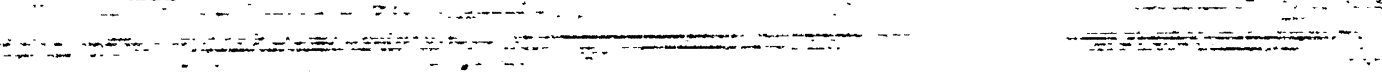

The objectives of the program were to design, build, and test a laboratory model of the RAPTOR gun and to demonstrate the RAPTOR gun's capability of breaking concrete slabs in a controlled manner.

\section{$1.2 \quad$ Rifle Experiments}

There is a wealth of experimental data in the literature on the impact of long slender rods into concrete slabs. However, there is very little data in the literature on concrete slab penetration by small projectiles (e.g., roughly 1/8-1/4 inch diameter for RAPTOR concept) in the velocity range of interest. Before the actual experimental RAPTOR gas gun was constructed, it was decided that a preliminary set of concrete target impact tests should be carried out using bullet-like steel projectiles launched using a conventional high power rifle. The objective of this preliminary test series was to determine if cracks in the target could be propagated between impact points. The data is limited in its application since the maximum velocity achievable for a 2.5 grams steel projectile was about $3000 \mathrm{ft} / \mathrm{s}$ and, as a result, only relatively thin concrete targets were tested. 


\section{CRADA BNL-C-96-01}

For these experiments a 300 Wheatherby Magnum rifle was used to launch steel projectiles into concrete targets of two and four inches thick. Four different nose shaped steel projectiles, all roughly 2.5 grams in weight, were fired. As shown in Figure 1, the rifle was mounted vertically on a frame constructed of steel channels (e.g., uni strut.) The concrete target was positioned flat on a bed of sand about 18 inches below the end of the barrel. The rifle was fired from a remotely located control room via a linkage system between the rifle trigger and the plunger of a solenoid. In order to achieve maximum velocity, 22 caliber projectiles were used in conjunction with a plastic sabot designed to fit into a 30-caliber cartridge. According to the Hornady Handbook for Cartridge Reloading the maximum powder charge (of type IMR4350) for a 7.1 gram bullet is 86.7 grains of powder. Two powder loads ( 75 and 88 grain IMR 4350) were used in the cartridges in order to achieve two projectile velocities possible (i.e., $2200 \mathrm{ft} / \mathrm{s}$ and $3000 \mathrm{ft} / \mathrm{s}$ ), one being the maximum possible.

For the two-inch thick concrete target, only the high velocity projectiles perforated the target. For both the high and low velocities, the impact of the projectile on the concrete target resulted in a crater on the top surface of the target at the point of impact. The size of the crater was not found to correlate with the projectile nose shape or its velocity but more on the size of the stone aggregate encountered by the projectile. For example, if the projectile hit a large stone near the surface, the size of the crater would be large and the penetration depth would be less compared to if the projectile encountered a small or no stone at all. In the two-inch target a crater also formed on the back side of the target (i.e., scabbing) directly behind the point of contact. The primary purpose of the RAPTOR gun is to section concrete slabs, i.e., fire projectiles in a line to have a crack establish through each impact point such that a portion of the target separates from the main piece. For the $2 "$ thick target, sectioning was accomplished by firing projectiles every six inches in a straight line offset from the target edge by six inches.

For the four-inch thick-concrete target, the high velocity projectiles penetrated between one and two inches depending on the aggregate encountered. As in the testswith the two-inch target, a crater was formed the point of impact. Howeyer, no crater formed on the back face...Sectioning of the four-inch target was accomplished by firing projectiles every three inches in a straight line and offset from the target edge by three inches. However fring the projectiles at a spacing of five inches, offset from the target edge by five inches, resulted in surface=cracking across the target but not completely thru the target

:-:-

The rifle tests were successful in demonstrating the concept of crack propagation between impact points. Based on the rifle test.results, it was apparent that in order to efficiently breakup 4 inch thick or greater concrete targets, velocities in excess of the $3000 \mathrm{ft} / \mathrm{s}$ upper limit for the rifle would be required. This provided the motivation to develop a gas gun to fire the projectiles at velocities on the order of $5000 \mathrm{ft} / \mathrm{s}$.

\subsection{Free-Piston Gas Gun Concept}

The basic components of a free piston compressor are shown in Figure 2a. The main component of the device is a smoothbore tube, called the compression tube, which contains a free moving piston. The tube is connected on one side to a gas reservoir and the other side to some other application dependent extension. The piston is initially at rest at the end of the compression tube and the reservoir is pressurized with gas, typically air. The piston is initially isolated from the high pressure gas either through a fast acting valve or a burst diaphragm (i.e., a thin metal or plastic foil which is calibrated to break at a given pressure differential across it). When the piston is exposed to the high pressure, it accelerates down the compression tube pressurizing the gas ahead. The piston acceleration continues to the point where the pressure on both the front and rear face of the piston is equal. From this point on, the piston undergoes a continuous deceleration 


\section{CRADA BNL-C-96-01}

since the pressure on the front face of the piston becomes larger than that at the rear. Eventually all the momentum of the piston is expended, i.e., converted into potential energy of the compressed gas ahead of it, and the piston momentarily comes to a rest. At this point in the piston cycle, the pressure and temperature of the gas ahead of the piston is at its maximum. The magnitude of both the pressure and temperature are governed by the compression ratio, i.e., the ratio of the gas volume ahead of the piston at the start and end of the piston stroke, and the ratio of the specific heats of the gas. After the piston comes to rest the pressure on the front piston face is greater than the rear face, and as a result, it starts to move in the opposite direction. The piston approaches its initial position, but never quite reaches it due to frictional and heat losses to the compression tube wall. This cycle continues, with decreasing amplitude, until the piston comes to rest at some equilibrium position where the pressure on both faces of the piston is equal.

The free-piston compressor described above has been used in several applications. If the front end of the free-piston compressor is rigidly closed off, as shown in Figure 2a, it can be used to study the physical properties of gases at high pressure and temperature. The sudden expansion of the high pressure gas produced by the free piston compressor, via a burst diaphragm, is used in several applications. For example, by connecting the free-piston compressor to a smooth bore tube downstream from the diaphragm, it can be used to generate shock waves for studies in gas dynamics (see Figure 2b). If a converging-diverging nozzle - is placed downstream of the diaphragm, the high pressure gas can be expanded to generate supersonic or hypersonic flows for studies in aircraft aerodynamics and propulsion (see Figure 2c).

As shown in Figure 2d, by placing a barrel loaded with a projectile downstream of the diaphragm, the expansion of the high pressure gas can be used to launch the projectile at a very high velocity. This last concept was established as early as 1957 ; when Crozier and Hume developed a - piston compressor This technique has been used extensively in the field"of supersonic aerodynamics.-.

- Typically models of supersonic aircraft or missiles are launched at a ballistic range and high speed

..... photography-of the projectile flight is taken. This device has also been used extensively for investigationswhich parallel-our objectives, i.e., to launch projectiles into targets in order to study projectile penetration

$\therefore-$ into-various-materials $=$ However, to the best of our knowledge, the device has never been used to breakup

concrete by crack propagation between impact points.

\subsection{Free-Piston Gas Gun Calculations}

For the R-APTOR design, the dimensions of the critical gas gun components were established based on numerical simulations of the gas dynamics and the piston and projectile dynamics. The calculations were performed by Jacques Belanger from the University of Minnesota using a code which was developed to simulate the free-piston shock tunnel T5 located at the California Institute of Technology. The gas dynamics is solved using the well-established method of characteristics. The calculation results will be provided in this section, a detailed technical description of the model is included in Appendix A. The results are based on the following gun dimensions and initial conditions:

Compression Tube

Length $=2.0 \mathrm{~m}$ (78.7 in)

Diameter $=50.8 \mathrm{~mm}(2 \mathrm{in})$

Piston Mass $=3 \mathrm{~kg}(6.6 \mathrm{lb}$.) 
CRADA BNL-C-96-01

Barrel

Length $=2.0 \mathrm{~m}(78.7 \mathrm{in})$

Diameter $=7.6 \mathrm{~mm}(0.3 \mathrm{in})$

Projectile Mass $=3.0 \mathrm{~g}(0.11 \mathrm{oz})$

Diaphragm burst pressure $=60 \mathrm{MPa}(8700 \mathrm{psi})$

Initial Conditions

Air reservoir pressure $=5.5 \mathrm{MPa}(800 \mathrm{psi})$

Helium pressure $=281 \mathrm{kPa}(40.8 \mathrm{psia})$

Shown in Figure $3 a$ is the predicted piston velocity versus piston distance traveled (actually the graph abscissa is distance to the diaphragm, which is $2 \mathrm{~m}$ less the piston travel distance). The piston starts off with zero velocity at the right-hand side and moves to the left. The piston achieves a peak velocity of about 80 $\mathrm{m} / \mathrm{s}$ after 1.6 meters of travel. As shown in Figure 3b; during the early times the helium pressure increases very slowly. As the piston approaches the end of the stroke the helium pressure rapidly increases and the piston decelerates. The helium pressure reaches the diaphragm burst pressure of $60 \mathrm{MPa}$ when the piston is $8 \mathrm{~cm}$ from the end of the compression tube, corresponding to a time of $38 \mathrm{~ms}$ after release of the piston. The helium pressure and piston velocity versus time from piston launch, around the time of diaphragm rupture is plotted in Figs $4 a$ and $4 b$, respectively. The vertical line shown in Figs $4 a$ and $4 b$ correspond to the time of diaphragm rupture. The piston velocity is $43 \mathrm{~m} / \mathrm{s}$ at the time of diaphragm burst, after which it comes to rest and re-accelerates in the opposite. direction (negative velocity). Figure $4 \mathrm{~b}$ indicates that the peak helium pressure_is $89 \mathrm{MPa}$, which is substantially above the diaphragm rupture pressure. The time elapsed from:piston-release to maximum forward motion is roughly $39 \mathrm{~ms}$. A plot of the projectile velocity. versus distance and time from piston launch is given in Figures $5 \mathrm{a}$ and $5 \mathrm{~b}$, respectively. The projectile requires roughly 2 ms to travel the distance of the barrel, and the velocity of the projectile when it leaves the barrel is $1770 \mathrm{~m} / \mathrm{s}$.

. This type of calculation provides a very good guide for the sizing of the gas gun components, and initial - pressures required to achieve the projectile velocities of interest to the program (i.e., $5000 \mathrm{ft} / \mathrm{s}$ or $1524 \mathrm{~m} / \mathrm{s}$ ): - However, the calculations assume isentropic conditions and do not take into account any pressure losses at changes in cross-sectional area; so the predictions will tend to be overestimated. In the Calibration Results section of the report some comparisons of measurements and calculations are made.

\section{EXPERIMENT DESCRIPTION}

\subsection{Facility Location}

RAPTOR is located in the southeast corner of the Experimental Hall of the Neutral Beam Test Facility, whose location relative to other major BNL facilities is shown in Figure 6. Shown schematically in Figure 7 is the overall layout of the Experimental Hall, indicating the location of equipment used in other experiments. The Experimental Hall concrete walls are 18 inch thick, except near the plug door entrance where the wall thickness is 36 inches. The Control Room basement walls are 15 inches thick, and are separated from the Experimental Häll south wall by $10 \mathrm{ft}$ of sand backfill. 


\section{CRADA BNL-C-96-01}

The gas gun is partially enclosed by a $10 \times 16 \mathrm{ft}$ room constructed of concrete blocks stacked 6 feet high with a total wall thickness of 15 inches. A schematic showing the position of the gas gun within the room is given in Figure 8. The gas gun is mounted in the horizontal position on a uni strut frame and the concrete target is positioned vertically next to the eastern wall of the block room. Also shown in Figure 8 is the position of the helium and air compressed gas cylinder behind the western wall of the room, out of line of sight from both the target and the high pressure end of the compression tube. Also shown is the position of a small vacuum pump which is used to evacuate the compression tube prior to filling with helium.

\section{$2.2 \quad$ Free-Piston Gas Gun}

The basic concept of the free-piston gas gun was given in the Introduction, in this section the detail design of the RAPTOR gas gun is described. A schematic of the gas gun assembly and supporting gas system is given in Figure 9. Two photographs of the gas gun components are given in Figure 10, which will be referenced in the following description of the main gas gun components. Also, provided in this section is a description of the basic operating procedure of the gas gun.

\section{Gas Reservoir}

The gas reservoir, as clearly seen in the photographs shown in Figure 10, is located at the end of the gun, opposite the barrel. The gas reservoir is an ASME Code Stamped pressure vessel which has a maximum allowable-working pressure of $1500 \mathrm{psig}$ at room temperature. The.vessel is equipped with a relief valve, see bottom photograph in Figure 10, set according the ASME Coderequirements. It is constructed from mild carbon steel and has a volume of roughly 0.88 cubic feet (10)inchinier-diameter and 19 inches long). A single port is provided for admitting air from a compressed gas cylinder. The gas reservoir is mated to the - compression tube via a bolted flange arrangement where the transition-from the larger diameter of the reservoir to the smaller compression tube diameter is through a tailored nozzle.

\section{Compression Tube}

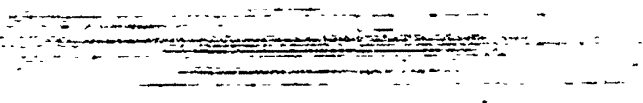

The compression tube, half shown in the top photograph given in Figure 10, is 66 inches long with an innerdiameter of 2 inches. The inner surface of the tube is honed in order to reduce the friction between the tube and the moving piston. The pressure in the compression tube is transient and the pressure behind the piston is different from that ahead of the piston. Initially the pressure behind the piston is higher than ahead of the piston with the maximum being that of the initial reservoir pressure. As the piston moves down the tube the pressure behind the piston drops and the pressure ahead increases. The pressure ahead increases very rapidly near the end of the piston stroke, i.e., roughly the last 12 inches. Therefore, there is no maximum pressure that the entire vessel is exposed to, e.g., the reservoir end of the compression tube is never exposed to the maximum pressures which the end of the compression tube is exposed to. The compression tube wall thickness was chosen based on predictions of the transient pressure in the compression tube. The compression tube was designed for a maximum allowable working pressure of $100 \mathrm{MPa}(14700 \mathrm{psig})$.

The compression tube.is.equipped with three ports. The port at the barrel end is fitted with a piezoelectric pressure transducer which measures the pressure transient in the helium gas ahead of the piston. A second port, located in the opposite end flange, is used to vent the air behind the piston after completion of an experiment and to evacuate the air in this same space prior to an experiment. The action of evacuating this 


\section{CRADA BNL-C-96-01}

air also draws the piston back to its initial position for the start of the experiment. The last port located in the tube section is used for evacuating the gas from ahead of the piston and then filling this space with helium from the compressed gas cylinder.

\section{Pision}

The efficiency of converting the internal energy of the air in the reservoir into internal energy of the helium at the end of the compression tube hinges on the performance of the free piston. The two dominant factors are, firstly, the sliding friction between the piston and the compression tube must be minimized, and secondly, the leakage of high pressure helium or air across the piston must be minimized. The piston is cylindrical in shape with two reinforced Teflon guide rings, one at each end, which act as bearing surfaces, and one elastomer 0 -ring at the front end for sealing purposes. Note that there is no contact between the honed inner surface of the compression tube and the metal piston. Teflon is the material chosen for the guide rings because of its excellent wear and frictional properties. The steel piston has a one inch diameter tungsten core which is used to increase the piston weight to $3 \mathrm{~kg}$. A polyurethane bumper is mounted on the front face of the piston in order to absorb the piston impact with the barrel end of the compression tube.

\section{- Barrel}

The compression tube is connected to the barrel through a nozzle-diaphragm assembly. The constant wall thickness barrel is 72 inches long with an internal diameter of 0.3 inches. The projectile is initially positioned in the barrel; just downstream of the diaphragm. When the diaphragm bursts, helium is introduced into the barrel, effectively propelling the projectile. The pressure in the barrel is transient and essentially follows the pressure-in the end of the compression tube less a small pressure drop associated with the contracted-flow at the orifice. The barrel wall thickness was chosen based on the same maximumallowable working pressure of $100 \mathrm{MPa}$ that the compression tube was designed for. Note the barrel is screwed into the primary diaphragm flange which is bolted to the compression tube flange. The aluminum diaphragm is squeezed between these two flanges which are equipped with Viton elastomer seals. An instrument port, which houses a piezoelectric pressure transducer is machined into the primary diaphragm-flangetomeasure the helium pressure in the barrel.

\section{Projectiles}

Two different types of projectiles were used in the tests. The rifle tests used projectiles which were similar in size to a 22-caliber bullet. The main difference is that the projectiles are made from 4340 steel, and hardened to a RockwellC of 40 . The projectiles are inserted into a commercial plastic sabot which enables the use of smaller caliber bullets in a rifle in order to achieve higher velocities. The sabot weight is $0.4 \mathrm{gm}$. In the initial phase of the gas gun tests a similar projectile was used. This projectile was $2.5 \mathrm{gm}, 0.22$ inches in diameter, and roughly 0.59 inches long with an ogive nose with a radius of curvature equal to 0.22 . In the later phase of testing, it was decided to go to a smaller diameter projectile in order to increase the penetration depth. For these tests, commercial 1 inch long, 0.125 diameter cement.nails were used. The nail head diameter was reduced to 0.22 inches so that it could be inserted into the plastic sabot. The nails come with a soft plastic collar which is used to center the nail in the barrel. Figure 11 shows a photograph of the two projectiles and sabot described above. 


\section{CRADA BNL-C-96-01}

\section{Isolation Valve}

The isolation valve is located between the gas reservoir and the compression tube, as can be viewed in the photograph given Figure 10. The isolation valve is a pneumatically actuated full-bore 2 inch NIPCO ball valve. The pneumatic actuator, which is the white box-shaped object above the valve in Figure 10, is equipped with a spring return such that when the actuator air pressure is vented to atmospheric the actuator automatically closes the valve. The pneumatic actuator is operated via a three-way control solenoid valve which can either pressurize the actuator to open the valve or vent the actuator to close the valve.

The isolation valve is not required to operate the gas gun. It serves two purposes; 1 ) integral part of the interlock system, i.e., prevents the firing of the gun, and 2) it is used to save the compressed air remaining in the reservoir following an experiment. If the valve is not used, the pressurized air remaining in the reservoir would have to be purged in order to change the diaphragm for the next experiment. If the gas gun is operated with a reservoir pressure of $550 \mathrm{psig}$ (based on numerical calculations) and the gas is vented after each experiment one would only be able to run five experiments per 2200 psig standard 1 A compressed gas cylinder (internal volume of 1.55). During an experiment the reservoir pressure only drops about $11 \mathrm{psi}$ from its initial $550 \mathrm{psig}$ as a result of the expansion into the compression tube. This is due to the small internal volume of the compression tube relative to the reservoir. Therefore, with the valve in place and by topping off the reservoir after each experiment one can run well over one hundred experiments with the same bottle of compressed air.

\section{Double-Diaphragm}

- ... The double diaphragm assembly consists of the three consecutive flanges located at the end of the

$\ldots \ldots$ compression tube. For the most efficient operation of a free-piston compressor the piston should be instantaneously subjected to the high pressure gas in the reservoir. Since the time required for the piston to complete its stroke is only about 40 milliseconds the opening time required for a valve would have to be at least an order of magnitude faster than this.-Clearly this type of performance cannot be achieved from a $\Rightarrow$ standard solenoid or air actuated valve-The-most common method for performing this task to use a diaphragm which ruptures when the back pressure is above a critical pressure. The time required for the diaphragm to open depends on the thickness and material properties of the diaphragm. In a standard single diaphragm system the reservoir pressure is raised until the diaphragm bursts. Since the calibration of the burst pressure always has some uncertainty, it is difficult to consistently operate the diaphragm at a prescribed pressure. To overcome this shortfall, a double-diaphragm is used where the pressure in the gas space between the two diaphragms can be varied. In this approach the intermediate space between the diaphragm is filled to half the pressure difference between the high and low pressure across the doublediaphragm. The strength of the two diaphragms is chosen such that they can support these pressure differentials. In order to burst the diaphragms the gas in the intermediate space is vented so that the first diaphragm bursts leading to the opening of the second diaphragm. By this method one can accurately prescribe the initial pressure in the gas reservoir at the time of diaphragm rupture.

\section{Gas Handling System}

The gas handling system for RAPTOR is shown schematically in Figure 9, and can be seen in the photographs provided in Figure 10. The high pressure helium and air is stored in standard 1A compressed gas cylinders. The gas delivery system to the gas gun uses two-stage pressure regulators to reduce the 


\section{CRADA BNL-C-96-01}

cylinder pressure to slightly higher than the required pressure. For example, for air the regulator pressure is set to about 800 psig and for the helium the regulator pressure is set to about 100 psig. As shown in the Figure 9, there are four gas injection points into the gas gun, 1) in the reservoir, 2) in the double diaphragm cavity, 3) in the compression tube flange next to the double diaphragm and 4) in the compression tube next to the double diaphragm. The gun is valved off at these four locations. Except for the isolation valve, all valves are $1 / 4$ inch Whitey " 40 " series ball valves. The stainless steel tubing used in the gas delivery system is $1 / 4$ inch outer-diameter with a 0.035 inch wall thickness. All fittings used in the gas delivery system are stainless steel Swagelok.

\subsection{Concrete Targets and Stand}

Concrete targets were prepared in a variety of sizes and thicknesses, enumerated in Table 2-1. They were poured on site in wooden frames, using a water/cement ratio which gives a nominal strength of $3000 \mathrm{psi}$ after a 28 day cure. As indicated, some of the targets have steel reinforcement wire, of the sort used in sidewalks.

Table 2-1. Concrete Targets

\begin{tabular}{||c|c|c|c|c||}
\hline $\begin{array}{c}\text { Thickness } \\
\text { (inches) }\end{array}$ & $\begin{array}{c}\text { Sides } \\
\text { (feet) }\end{array}$ & $\begin{array}{c}\text { Weight } \\
(\mathrm{lbs})\end{array}$ & $\begin{array}{c}\text { Reinforcemen } \\
\mathrm{t} .\end{array}$ & $\begin{array}{c}\text { Number } \\
\text { of pads }\end{array}$ \\
\hline 2 & 2 & 100 & -4 \\
\hline 2 & 2 & 100 & 2 \\
\hline 4 & $2-1 / 2$ & 310 & No & 6 \\
\hline 4 & $2-1 / 2$ & 310 & Yes & 2 \\
\hline 6 & -3 & 665 & $-\mathrm{No}^{-}$ & 3 \\
\hline 6 & 3 & 665 & Yes & 1 \\
\hline
\end{tabular}

Since the gas gun is mounted horizontally, the target is mounted vertically and normal to the gun centerline in a custom designed target stand, shown in Figure 12. The steel target stand consists of two fixed sides, and two side plates which can be translated in order to compress the sides of the target. Since the gun's position is fixed, the target is translated in two directions in order to vary the projectile impact location on the target. On a $x-y-z$ Cartesian co-ordinate system, if we assume that the gun orientation is in the $z$ direction target motion is in the $x-y$ plane. This is accomplished by mounting the target support stand on a battery powered pallet lift which can be seen in the photograph shown in Figure 12. The two degrees of motion is achieved by the back and forth motion of the cart and the up and down motion of the fork. 


\section{CRADA BNL-C-96-01}

\subsection{Projectile Velocity Measurement .}

The projectile velocity was measured using a commercial chronometer used by rifle enthusiasts to measure bullet velocities. The accuracy of the chronometer was checked using a home made system based on measuring the time for the projectile to pierce two aluminum sheets separated by a known distance.

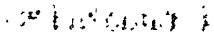

\section{5 is Experiment Video Monitoring \\ $\therefore$, tivents?}

Duringtheinormal operation of an experiment the experimental area is monitored by a video camera located inside the block room. After the Experimental Hall is cleared, the house lights automatically shut off, and auxiliary flood lights located in the block room are turned on. A video monitor located in the control room is used for real time viewing of the experiment. Every test is recorded on a VCR located in the control room for future review.

\section{s.t. \\ 2.6. Interlóck System \\ titis}

The safety interlock system used for RAPTOR is based on the redundant, fail-safe radiation access control system installed as a component of the NBTF. The main objective of the interlock system is to ensure that the gun is not'operated when personnel are in the Experimental Hall and that there is no danger to personnel replacing the various diaphragms on the gun with the air reservoir pressurized. In order to launch a projectile the free piston must be set into motion. This is done by exposing the rear face of the piston to high pressure air from the reservoir. The piston is isolated from the air-reservoir via-the isolation ball valve.

Therefore, ;if one can assure that this valve is closed; the gas gun cannot be fired and it can be considered to be in a safe state: As described earlier, the ball valve-is pneumatically actuated using $80 \mathrm{psig}$ instrument air andis normally closed (spring return). The preumatic actuator is controlled via-a three way solenoid valve which can either pressurize the actuator to open the valve or vent the actuator to close the valve via the spring return. The de-energized state of the solenoid valve is set such that the valve actuator is normally vented and thus the bail valve is closed. In order to actuate the ball-valve both $=24$ volts:d :c. power and $80 \mathrm{psig}$ instrument with any personnel in the experimental area, the solenoid valve which controls the ball valve actuator is interlocked.tithis is done by interrupting the instrument air supply to the solenoid valve when the interlock systemlis not satisfied. For the gas gun experiment, the only requirement for running an experiment and thus satisfyingthe interlock system, is that the Experimental Hall and the two tunnels be cleared of personnel. During this celearing procedure the experimental room housing the gas gun is also searched for personnel.

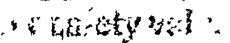

The existing NBTF interlock system starts with a monitor for the crash system of pull-chords and red mushroom emergency stop buttons. With the crash system satisfied, all doors closed and monitored, and the clearing sequence satisfied, the facility is considered SECURE. By removing the key from the plug door and placingititinto the RAPTOR experimental control panel, a sequence is initiated which signals the start of a RAPTOR testaiThe plug door is electrically locked (power is removed from the door motor circuits), the flourescent lights.within the Experimental Hall and the two tunnels are shut off, a 10 second $400 \mathrm{~Hz}$ warning tone is 3 broadcast over the facility public address system. Following this procedure the facility is considered LOCKEDiand the instrument air becomes available to the isolation valve.

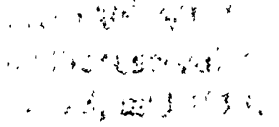




\section{CRADA BNL-C-96-01}

\subsection{Control and Data Acquisition System}

The control system is PC based, using two external Strawberry Tree Data Shuttle units which include both the data acquisition card and the terminal panel in one unit. The units can be powered externally from a 120 Volt outlet via a transformer, or via the computers power source. Strawberry Tree Workbench software is used to control the data acquisition cards. This system accommodates several channels of analog input and digital input/output. The digital output channels are used to operate the pneumatically controlled valves.

- Each digital output channel is protected by an Optical Isolator Module which isolates the data acquisition cards from any high voltage surges (e.g., 1500 Volts). The modules are used as relays to switch the externally supplied 24 volts d.c. on and off to the low power electric solenoid valves, which actuate the main valve pneumatic actuators. The analog input channels are used to measure current output from two strain gauge type pressure transducers. The pressure transducers are used to measure the air pressure in the reservoir and the initial helium pressure in the compression tube. The pressure transducers are calibrated at a frequency of once a month. The digital output channels are used for controlling the solenoid valves which are used for loading and evacuating air and helium into the various gun components. In terms of data acquisition, during a typical experiment the voltage signal from two piezoelectric pressure transducers are recorded on a four channel high-speed LeCroy oscilloscope.

\subsection{Gas Gun Operating Procedure}

During the operation of the gas gun, the Experimental Hall is free of personnel and the gun is operated remotely from the control room. We will assume that the gun has just been fired such that all the diaphragms

-are-burst and air at a pressure just-below the initial reservoir pressure occupies the reservoir as well as the section of the compression tube behind the piston. At the end of the shot, as a result of the high presssure air acting on the back face of the piston, the piston will-be-located at its farthestownstream position next to the nozzle assembly. The first step is to close the isolation valve in order to conserve the remaining air in the reservoir and to vent the compression tube to the atmosphere. At this point personnel can enter the Experimental Hall to set up the gun for the next shot. The double diaphragm-assembly is opened and the expended diaphragms are removed.- The barrel/compression tube-flanges are unbolted and the nozzle. assembly is extracted. Using a long wooden stick, the piston is pushed through the compression tube and out double diaphragm opening. The compression tube is then cleaned using a swab attached to the end of the stick. The piston is placed back into the reservoir end of the compression tube and new diaphragms are put in place. The nozzle assembly, along with the downstream double diaphragm flange are tightened. A new projectile is inserted into the barrel and the barrel is screwed into place. The vacuum pump is turned on, the safety valve for the instrument air is closed, and all personnel are cleared from the Experimental Hall.

The data acquisition and control computer is turned "on," the Workbench software is "executed," and the appropriate Workbench worksheet is loaded. This brings up the main control panel on the computer screen where all the valve actuators and pressure gage meters appear. For the remaining description refer to Figure 9 for the valve numbering scheme. The isolation valve is opened by actuating valve 10 . The air is evacuated from the compression tube, on either side of the piston, by actuating valves V5, V1, and V2. The helium is then added to the compression tube ahead of the piston to a prescribed pressure (e.g., 41 psia) by actuating valves V6, V1, V2 and V7 for the pressure gage. Next, air is introduced into the double diaphragm cavity and the reservoir to a pressure roughly half of the prescribed initial air reservoir pressure by actuating valves $\mathrm{V} 8, \mathrm{~V} 3$, and $\mathrm{V} 4$ (note the pressure transducer for the reservoir is not valved off). The reservoir is then 


\section{CRADA BNL-C-96-01}

topped off with air to the prescribed initial pressure for the test (e.g., 750 psia) by actuating valves V8 and V3. The firing of the gun is initiated by venting to atmosphere the air from the double diaphragm cavity. This is done incrementally by first venting the panel by actuating valve V9, then venting the double diaphragm cavity into the panel volume by actuating valve V4. This two step process is continued until the diaphragm bursts. That is, this causes the first diaphragm to burst injecting air into the double diaphragm cavity to a pressure slightly below the initial reservoir pressure. This then causes the second diaphragm to burst injecting air into the compression tube, thereby accelerating the piston and pressurizing the helium ahead of it. When the helium pressure reaches the main diaphragm burst pressure (e.g., 10,000 psia) it ruptures. This starts the expansion of the high pressure helium into the barrel, resulting in the acceleration of the projectile down and out of the barrel. At the same time the piston recoils slightly and then reaccelerates towards the barrel impacting and coming to rest at the front face of the nozzle.

\section{CALIBRATION TESTS}

\subsection{Diaphragm Burst Pressure}

The gas gun uses several calibrated burst diaphragms. The material used for the diaphragms is commercial grade 1100-0 aluminum. The double diaphragm assembly uses two 4 inch diameter diaphragms, of which only an area corresponding to 2 inches in diameter is exposed to pressure. The primary diaphragm consists of a single 2.5 inch diameter diaphragm with a pressure exposed area corresponding to 0.306 inches in diameter. The diaphragms used in the double diaphragm assembly were calibrated by loading the first diaphragm and leaving out the second one. Air was-slowly added to the reservoir until the diaphragm burst ${ }^{-}$ and the pressure.was noted. For the primary diaphragms, the burst pressure was obtained from the transient helium pressure signals obtained from tests with the piston set in motion.-The time of rupture is identified by as sudden rise in pressure in the pressure signal recorded just downstream of the diaphragm. The burst pressure is then obtained via the helium pressure signal recorded at the end of the compression tube at the measured time of diaphragm rupture. The burst pressure versus diaphragm thickness is given.in Table 3.1.

\begin{tabular}{|c|c|c|c|}
\hline \multicolumn{3}{|c|}{ Table 3.1. Diaphragm Burst Pressure } \\
\hline Double Diaphragm & \multicolumn{2}{c|}{ Primary Diaphragm } \\
\hline Thickness (inches) & $\begin{array}{c}\text { Ave. Burst Pressure } \\
\text { (psi) }\end{array}$ & $\begin{array}{c}\text { Thickness (inches) } \\
\text { Ave. Burst Pressure } \\
\text { (psi) }\end{array}$ & \begin{tabular}{c} 
Ave \\
\hline 0.015
\end{tabular} \\
\hline 315 & .015 & 3100 \\
\hline 0.020 & 600 & .020 & 4100 \\
\hline & & .025 & 6000 \\
\hline
\end{tabular}




\section{CRADA BNL-C-96-01}

\subsection{Maximum Helium Pressure}

Tests were performed to measure the maximum helium pressure achieved when the end of the compression tube is closed. This was achieved by inserting a very thick primary diaphragm which would support the expected maximum helium pressure. The peak helium pressure was recorded for various combinations of initial helium pressure in the compression tube and initial air pressure in the reservoir. Two air reservoir pressures were used, $500 \mathrm{psi}$ and $750 \mathrm{psi}$. With the air reservoir pressure fixed, the initial helium pressure was varied with a constraint on the minimum based on the resulting peak helium pressure being below the maximum allowable working pressure for the compression tube, i.e., 15000 psi. Shown in Figure 13 (top) is a typical pressure-time history recorded in the compression tube with the end closed. The test was performed with an initial air pressure of $550 \mathrm{psi}$ and initial helium pressure of $41 \mathrm{psia}$. The signal includes 9 pressure pulses which are generated as a result of the oscillatory motion of the piston. Since the helium is not vented out the end, the piston continues to oscillate until non isentropic effects (e.g., friction and heat loss) brings the piston to rest. The peak of each consecutive pressure pulse is diminished as the piston slows down and the stroke length is decreased. Of interest is the peak pressure which corresponds to the first pulse. The first pressure pulse is reproduced in Figure 13 (bottom) with the time scale reduced. The actual time for the piston to complete its compression stroke is about 30 milliseconds, however, the bulk of the pressure rise occurs in the last 5 milliseconds of the stroke. For this particular test, the peak helium pressure was about 9100 psi.

Shown in Figure 14 is a plot of the measured peak helium pressure as a function of initial helium pressure, for a fixed 500 psi reservoir pressure. Also shown in Figure 14 are predicted values obtained from the numerical code described earlier in the report. The results indicate that the measured peak pressure is consistently about $15 \%$-below the calculated value. These lower pressures can be attributed to pressure losses in the reservoir nozzle, frictional losses at the piston and heät losses from the compressed helium. The plot shows that the minimum amount of initial helium is about $23.5 \mathrm{psia}$, i.e., above this limit the peak helium pressure is higher than the compression tube maximum allowable pressure of $15000 \mathrm{psi}$. Similar tests were performed with a fixed air reservoir pressure of $750 \mathrm{psi}$. Again the measured peak helium pressure was about $15 \%$ below the calculated value. The minimum initial helium pressure=which resulted in a:peak helium pressure of 15000 psi-was determined to be 44 psia. These limits on the initial helium pressure are used to define the operating limits of RAPTOR(i.e., permissible initial air and initial helium pressure combinations).

\subsection{Projectile Velocity}

Early tests indicated that the projectile becomes aerodynamically unstable (i.e., projectile tumbles) once it leaves the barrel. This is based on observations that in many tests the projectile damage after impact was mainly concentrated on the side of the projectile. This instability can be attributed to the fact that the projectile does not spin on its axis, as is the case with a bullet fired from a rifled barrel. Therefore, in order to ensure that the projectile impacts the target head on, the target must be placed close to the end of the barrel. For proper operation of the chronograph, the manufacturer recommends that it be placed at least 4 feet from the end of the barrel. As a result, velocity measurements cannot be taken during a typical projectile launch and target impact test. Therefore, a series of calibration tests were carried out to determine the projectile velocity as a function of various parameters, including: reservoir pressure, initial helium pressure, primary diaphragm thickness, and projectile mass. For these tests the 22 caliber projectile was used exclusively, and the total projectile/sabot mass was varied between 2.5 and 2.91 gm by removing material off the back end of the projectile. Two primary diaphragm thicknesses were used, 0.025 and 0.032 inches. 


\section{CRADA BNL-C-96-01}

It was found that for these two diaphragm thicknesses tested the influence on the projectile velocity was minimal. The thicker diaphragm resulted in higher peak pressures because of the higher burst pressure.

Shown in Figure 15 is the pressure time histories recorded at locations before and after the diaphragm for a test with $500 \mathrm{psi}$ air in the reservoir and $30 \mathrm{psia}$ initial helium pressure. In this test the pressure transducer PT2 is located between the diaphragm and the projectile. When the diaphragm bursts a shock wave is generated and the pressure is measured by the transducer. Since the transit time for the shock wave is very small, the first indication of a pressure rise in PT2 defines the diaphragm rupture time which can then be used to determine the burst pressure from the pressure transducer PT1 signal. In this figure the rupture time is indicated by the arrow which appears at the same time on both signals. It is interesting to note that the diaphragm rupture time can also be deduced directly from the PT1 signal by the onset of some high frequency noise which appears on the signal. The source of this noise is either mechanical vibration caused by the sudden rupture of the diaphragm or some high frequency pressure oscillations associated with the outflow of helium into the barrel. The oscillations observed in the PT2 pressure transducer are the result of pressure pulse reflections between the throat and the projectile. If the projectile is placed immediately adjacent to the diaphragm, the pressure signal shown in Figure 16 is obtained. Note this test is with an initial helium pressure of $25 \mathrm{psia}$, and thus the peak pressure is slightly higher than in the test from Figure 15 . This fact aside, the pressure signal from PT2 is free of vibrations since initially there is no gap between the diaphragm and the projectile. The pressure rise in PT2 is delayed relative to the diaphragm rupture because the projectile requires a finite time to move past the PT2 port in order to expose the transducer to the high pressure helium.

The measured projectile velocity and peak helium pressure are plotted versus initial helium pressure in Figures 17 and 18 for $2.5 \mathrm{gm}$ projectile/sabot-and a reservoir pressure of 500 psi-and 750 psi, respectively. As one would expect both the projectile velocity and peak helium pressure decrease with increasing initial helium pressure. For a 500 psi reservoir pressure and $2.5 \mathrm{gm}$ projectile/sabot the maximum velocity measured was $4450 \mathrm{ft} / \mathrm{s}$ which was obtained with an initial helium pressure of $20 \mathrm{psia}$. For this test the peak helium pressure measured was $10847 \mathrm{psi}$ which is well below the 15000 psi maximum allowable working pressure for the compression tube. From Figure 14, under closed end conditions the peak helium pressure for this initial helium pressure would be well over the $15000 \mathrm{psi}$. Therefore, using the peak helium pressures measured under closed end condition to define the operating limits for open end conditions is very conservative. Much higher projectile velocities are achievable if the operating limit was defined based on the measure peak helium pressure under open end conditions. For a $750 \mathrm{psi}$ reservoir pressure and $2.5 \mathrm{gm}$ projectile/sabot the maximum velocity measured was $4635 \mathrm{ft} / \mathrm{s}$ which was obtained with an initial helium pressure of $40 \mathrm{psia}$. The corresponding peak helium pressure for this test was $11273 \mathrm{psi}$, once again well below the $15000 \mathrm{psi}$ limit. The highest projectile velocity measured is $5011 \mathrm{ft} / \mathrm{s}$ for a $1.8 \mathrm{gm}$ projectile/sabot achieved with an initial air and helium pressure of 750 psi and 40 psia, respectively.

\section{CONCRETE TARGET IMPACT TESTS}

For the impact tests the front surface of the concrete target was placed about 1-2 inches from the end of the barrel, and therefore velocity measurements were not taken. The objective of these tests were two fold, 1) measure penetration depth, and 2) measure the influence of impact spacing on target cracking. A total of 66 


\section{CRADA BNL-C-96-01}

impact tests were performed, using five different targets. Shown in Figure 19 is a schematic showing the various targets and projectiles used in the test series, along with the test run number associated with each impact point. Note only the first and last run numbers are shown in a row of impact points.

\subsection{Projectile Penetration}

The measurement of penetration depth as a function of projectile diameter, size, and velocity is very important for determining the proper combination of these parameters to crack a particular thickness concrete target. For example, for a 4 inch thick target one wants to achieve a projectile penetration on the order of 3 to 3.5 inches. Penetration of more than 3.5 inches is inefficient since residual projectile kinetic energy will be wasted. On the other hand, for a 4 inch thick target if the projectile penetration is only 2 inches it would be difficult to generate a crack completely through the target with a reasonable impact spacing. For a given projectile and projectile velocity, the penetration depth can vary considerably depending on the size of the aggregate and number of aggregate encountered by the projectile along its penetration path in the target. In the rifle tests, where the projectile velocity was limited to $3000 \mathrm{ft} / \mathrm{s}$, typically when a projectile encountered an aggregate it would either crack or dislodge the stone from the target, in either case the projectiles forward motion would cease. With the higher velocity achieved using the gas gun, the projectile penetrates through the stone by pulverizing it.

Target penetration depth is measured by inserting a screw driver into the hole until it bottoms out on the back of the projectile. The penetration depth is taken as the length of the portion of the screw driver which lies -within the hole plus the original length of the projectile. Figure 20 is a schematic which shows the measured - penetration depth for each of the tests indicated in Figure 19. Perforation of the 4 " targets was not observed in any of the tests. It. is interesting to note that the deepest penetrations.were observed in the reinforced 4"

thick target (see Figure 20e), the reason for this is unknown. Since the target remains intact it is not possible to_determine whether a projectile directly impacted the reinforcement wire. Table 4.1 summarizes the measured projectile penetrations achieved as a function of projectile dimension, mass and velocity.

Table 4.1. Projectile Penetration Measurements

\begin{tabular}{|c|c|c|c|c|c|}
\hline \multirow{2}{*}{$\begin{array}{c}\text { Diameter (in) } \\
\text { x length (in) }\end{array}$} & Mass (gm) & \multirow{2}{*}{$\begin{array}{c}\text { Velocity } \\
(\mathrm{ft} / \mathrm{s})\end{array}$} & \multirow{2}{*}{\begin{tabular}{l} 
\# of shots \\
\cline { 3 - 5 }
\end{tabular}} & & \multicolumn{2}{|c|}{ Penetration (in) } \\
\hline $0.22 \times 0.59$ & 2.5 & 3000 & 14 & 1.5 & \\
\hline $0.22 \times 0.59$ & 2.5 & 4500 & 16 & 2.0 & 0.3 \\
\hline $0.125 \times 1.5$ & 3.7 & & 1 & 3.7 & \\
\hline $0.125 \times 1.0$ & 2.7 & $4500^{*}$ & 31 & 2.9 & 0.4 \\
\hline $0.125 \times 0.75$ & 2.3 & & 2 & 2.8 & 0.1 \\
\hline $0.125 \times 0.5$ & 1.8 & $5000^{*}$ & 2 & 2.3 & 0.4 \\
\hline
\end{tabular}

* estimated based on measured velocity of similar mass 0.22 diameter projectile 


\section{CRADA BNL-C-96-01}

It is clear from Table 4.1 that for a given projectile mass, an increase in the velocity results in an increase in the penetration depth. However, simply increasing the velocity by decreasing the mass does not result in deeper penetration, as is the case with the $0.125 \times 0.5$ inch projectile compared to the heavier $0.125 \times 1.0$ inch projectile.

\subsection{Crack Propagation}

The main objective of the tests shown in Figure 19 was to determine the minimum impact spacing required for crack propagation. The impact point spacing for the tests from Figure $19 \mathrm{can}$ be determined by dividing the target width (e.g., 4" thick target is 30" $\times 30^{\prime \prime}$ and that of the 6" thick target is $36^{\prime \prime} \times 36^{\prime \prime}$ ) by the number of impact points plus one. For example, for a $4^{\prime \prime}$ thick target with five impact points across the length, the impact spacing is $30 " /(5+1)=5$ inches. The results of the tests on each of the targets is summarized below:

(A) A. 4 inch thick concrete target was tested with 0.22 inch diameter projectiles launched at $4500 \mathrm{ft} / \mathrm{s}$. Two series of tests (\#27-31, \#33-37) were performed, each with a projectile impact spacing of 5 inches. A crack propagated through all the impact points for each of the two series. However, the crack did not penetrate completely through the 4 inch thick target.

On the same 4 inch thick concrete target, a third series of tests (RUN \#38-43) was performed using 0.22 inch diameter projectiles launched at $4500 \mathrm{ft} / \mathrm{s}$ with a projectile impact spacing of 4 inches. In this case, the crack propagated through all the impact points and completely through thickness of the target.

(B) A-4 inch target, previously used in rifle tests, was used to determine if the smaller 0.125 inch diameter projectiles launched at $4500 \mathrm{ft} / \mathrm{s}$ could crack through the target with a 5 inch projectile impact spacing (RUN \#44-47). The crack propagated through all the impact points and completely through the target.

(C) A-6 inch-thick concrete target was tested with 0.125 inch diameter projectiles launched at $4500 \mathrm{ft} / \mathrm{s}$. Two series of tests were performed with projectile impact spacings of 4 inches (RUN \#57-64) and 6 inches (RUN \#65-69). For the 4 inch spacing series, the crack propagated through all the impact -points and completely through the target. For the 6 inch spacing, the crack did not propagate completely through the thickness of the target.

(D) A 4 inch thick concrete target was tested with 0.125 inch diameter projectiles launched at $4500 \mathrm{ft} / \mathrm{s}$. Two series of tests were performed with projectile impact spacings of 5 inches (RUN \#70-74) and 6 inches (RUN \#75-78). For both the 5 and 6 inch spacing tests, the crack propagated through all the impact points and completely through the target.

(E) A single test series (RUN\# 79-83) was performed on a 4 inch thick concrete target with reinforcement wire, using 0.125 inch diameter projectiles launched at $4500 \mathrm{ft} / \mathrm{s}$. For a 5 inch spacing test series, the crack propagated through all the impact points and completely through the target. Although the crack propagated completely through the target the target remained intact because of the reinforcement wire mesh. 


\section{CRADA BNL-C-96-01}

A photograph taken of the cracked 4" concrete target after the test series \#70-74 is shown in Figure 21 . In this particular test series five impact points, corresponding to a 5 " spacing, generated a clean cut across the length of the target. In this photograph the projectile holes can be observed in cross-section, as delineated by a white streak on the photograph. When the projectile first enters the target it penetrates through the aggregate, but the projectile velocity decreases, and eventually the projectile's forward motion is arrested by a stone. This photograph shows the precision cutting which can be accomplished with RAPTOR.

The target shown in Figure $19 \mathrm{~b}$ was used for many penetration tests where projectiles were impacted quasirandomly on the target. The photograph shown in Figure 22 was taken of this target after all the tests were completed. The photograph shows how a section of concrete pavement can be broken up into finite size chunks which can be carted away using conventional methods. The chunk size would be much more uniform if the impact spacing was better controlled.

\section{SUMMARY AND FUTURE WORK}

The RAPTOR program has met all its objectives which were set out at the start. The tests have successfully demonstrated the concept of concrete pavement breakup by the impact of high speed projectiles. It has been demonstrated that cracks can be propagated in 4 and 6 inch thick concrete slabs by repeated impacts of projectiles at a fixed spacing. The maximum impact spacings required for full crack penetration have also been identified for the various target thicknesses. It was also demonstrated that concrete targets with reinforcement can be cracked using similar projectile mass, velocity and spacing as used in a-similar thickness non-reinforced target.

As stressed at the start of the program the objectives were to design and build a laboratory RAPTOR which can be used to demonstrate the concept. Further testing can be performed with the existing gas gun. The gas gun is currently being used at roughly 70 percent of its capacity, which is the peak compression tube pressures are roughly 70 percent of the maximum allowable pressure. With permission from the Laboratory safety committee the gas gun could be used in the future at full capacity to increase the projectile velocity range and determine the affect of these higher velocities. on penetration depth and crack propagation maximum impact spacing:

The natural progression of the development of RAPTOR is to design and build a prototype version which can be taken out into the field to breakup in situ concrete pavement. This prototype would have to be compact such that it could easily be stored in a standard gas utility company van and be handled by a single person. The prototype would be equipped with automatic projectile loader and magazine, so that the operator can perform a typical task with minimum effort and complexity. The prototype would be equipped with other operator safety features such as a barrel silencer, and concrete fragment shroud. 


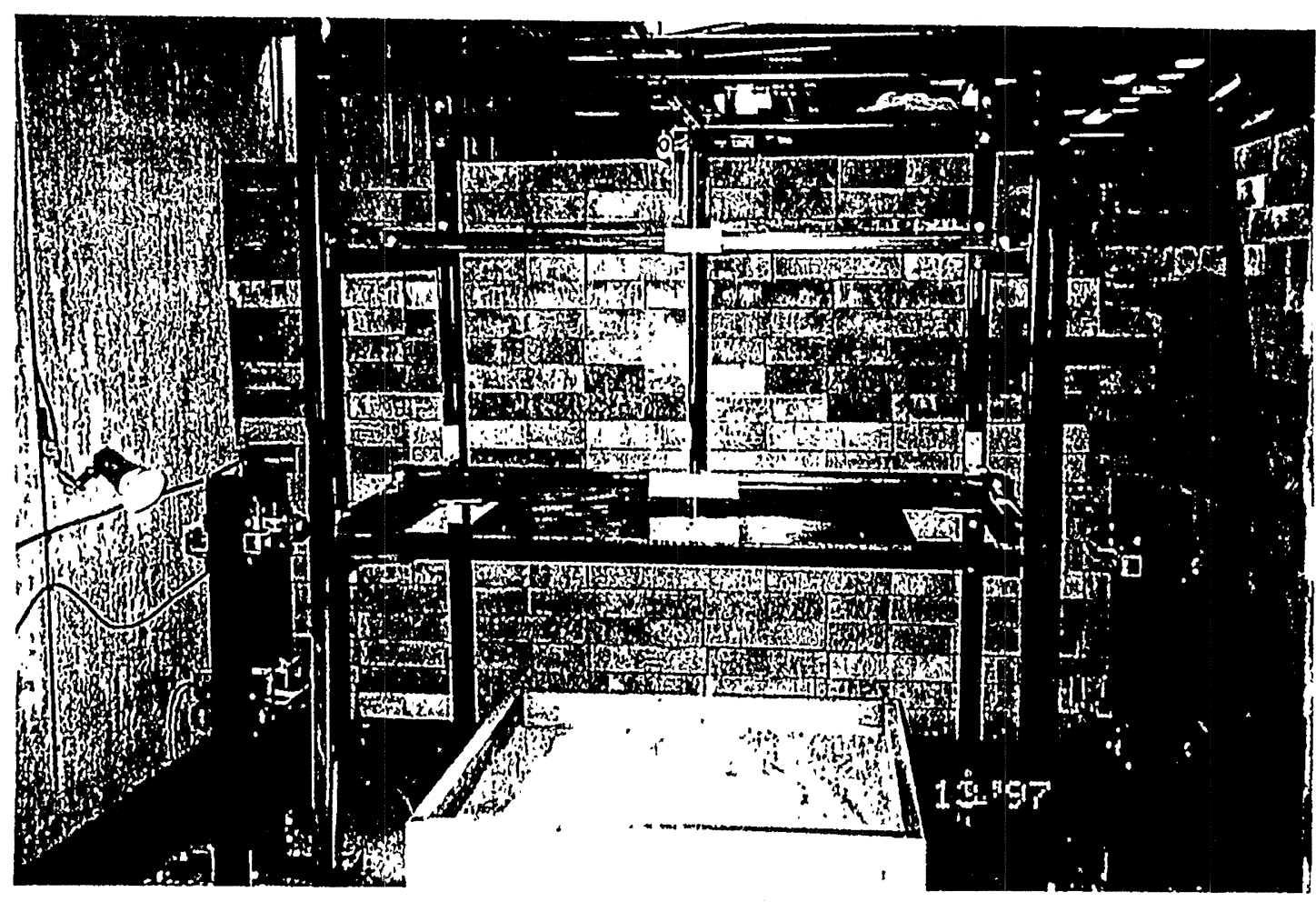

Figure 1: Photograph of the rifle test apparatus 


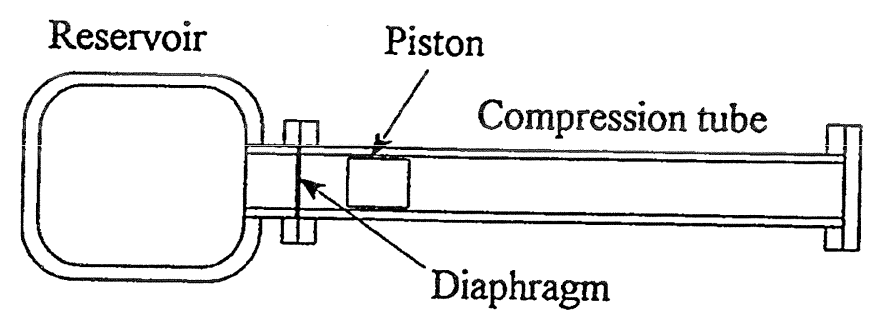

A) Basic Free-Piston Compressor

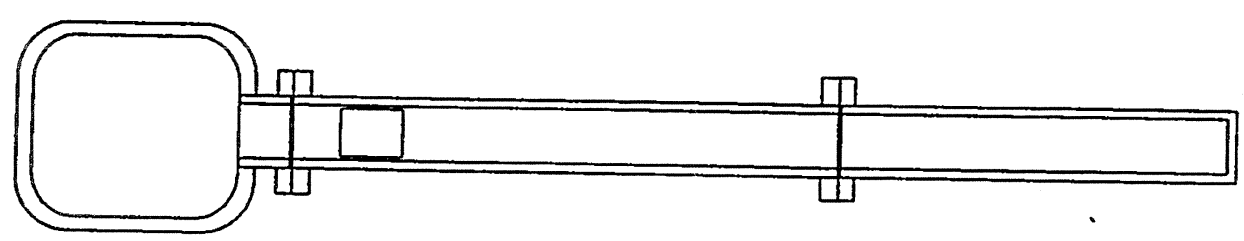

B) Shock tube driver

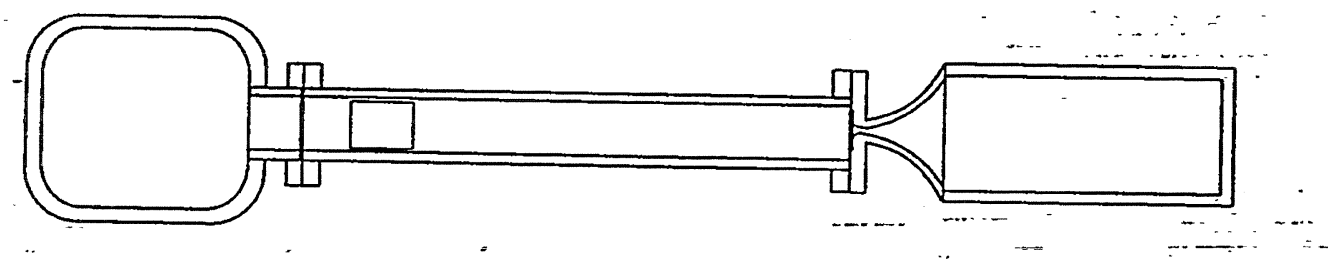

C) Hypersonic wind tunnel

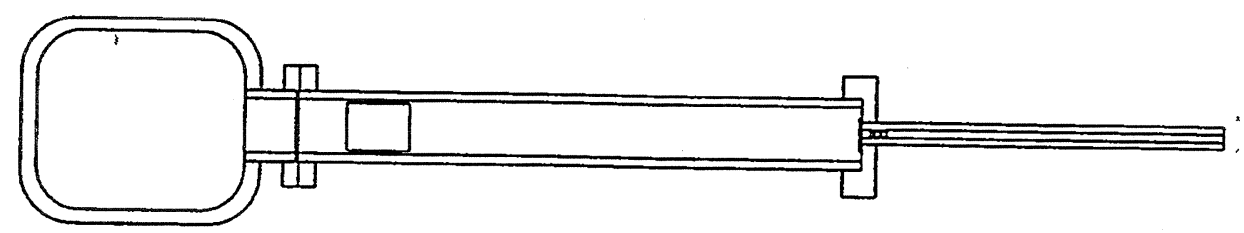

D) Two-stage gas gun

Figure 2: Schematics showing various applications 


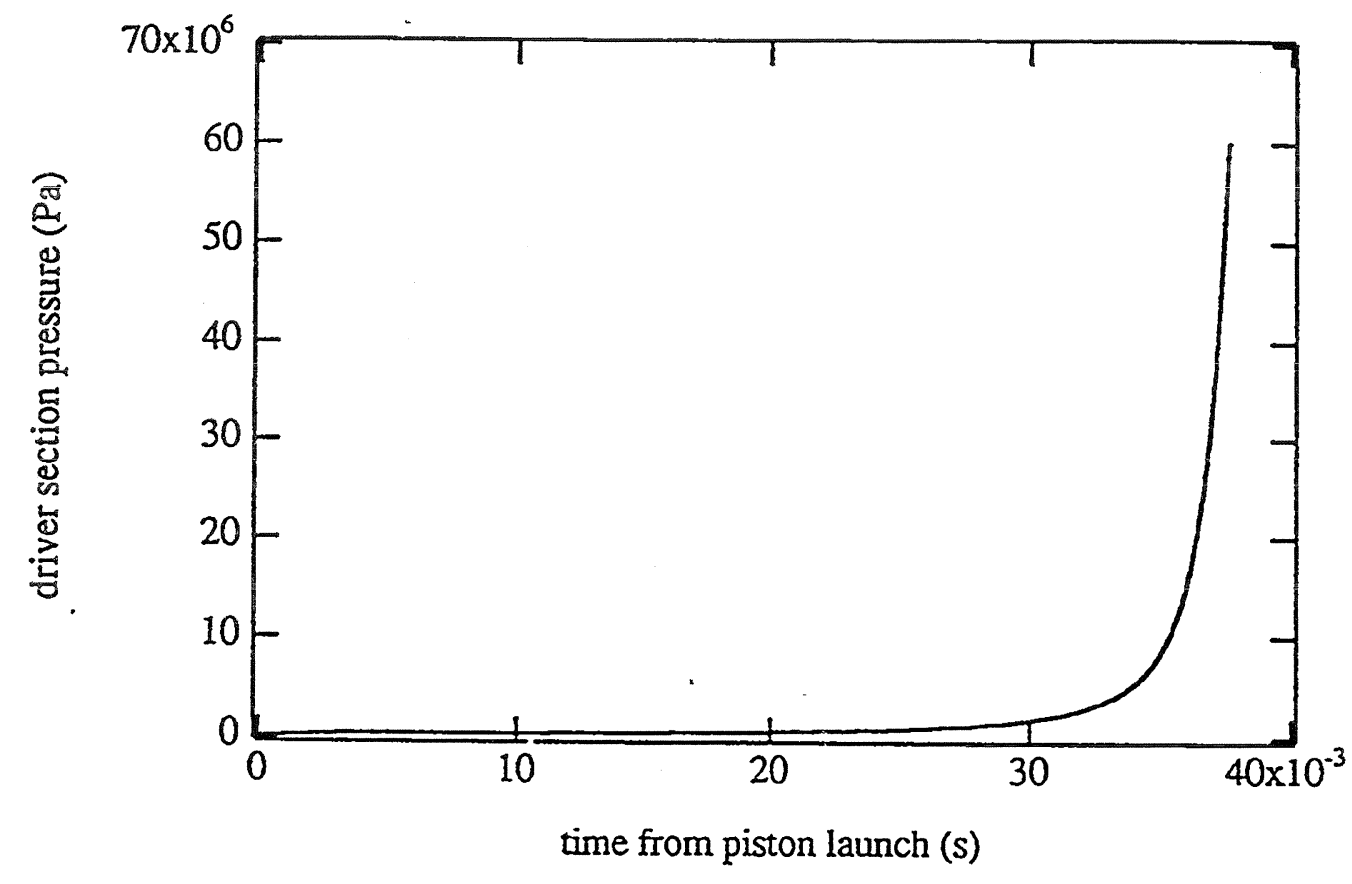

Figure $3 \mathrm{~b}$ : Predicted helium pressure versus time from piston release

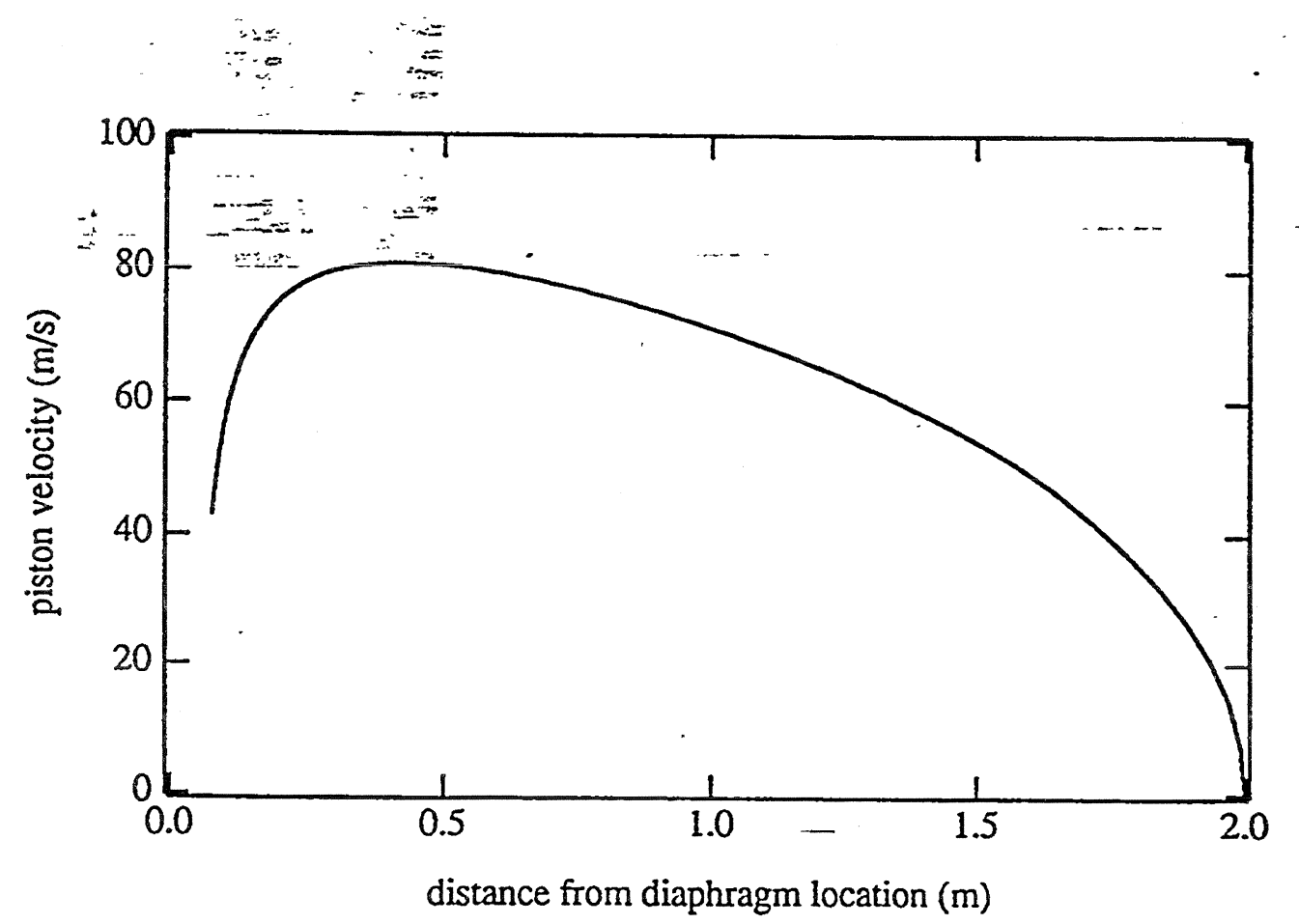

Figure 3a: Predicted piston velocity versus distance from diaphragm location 


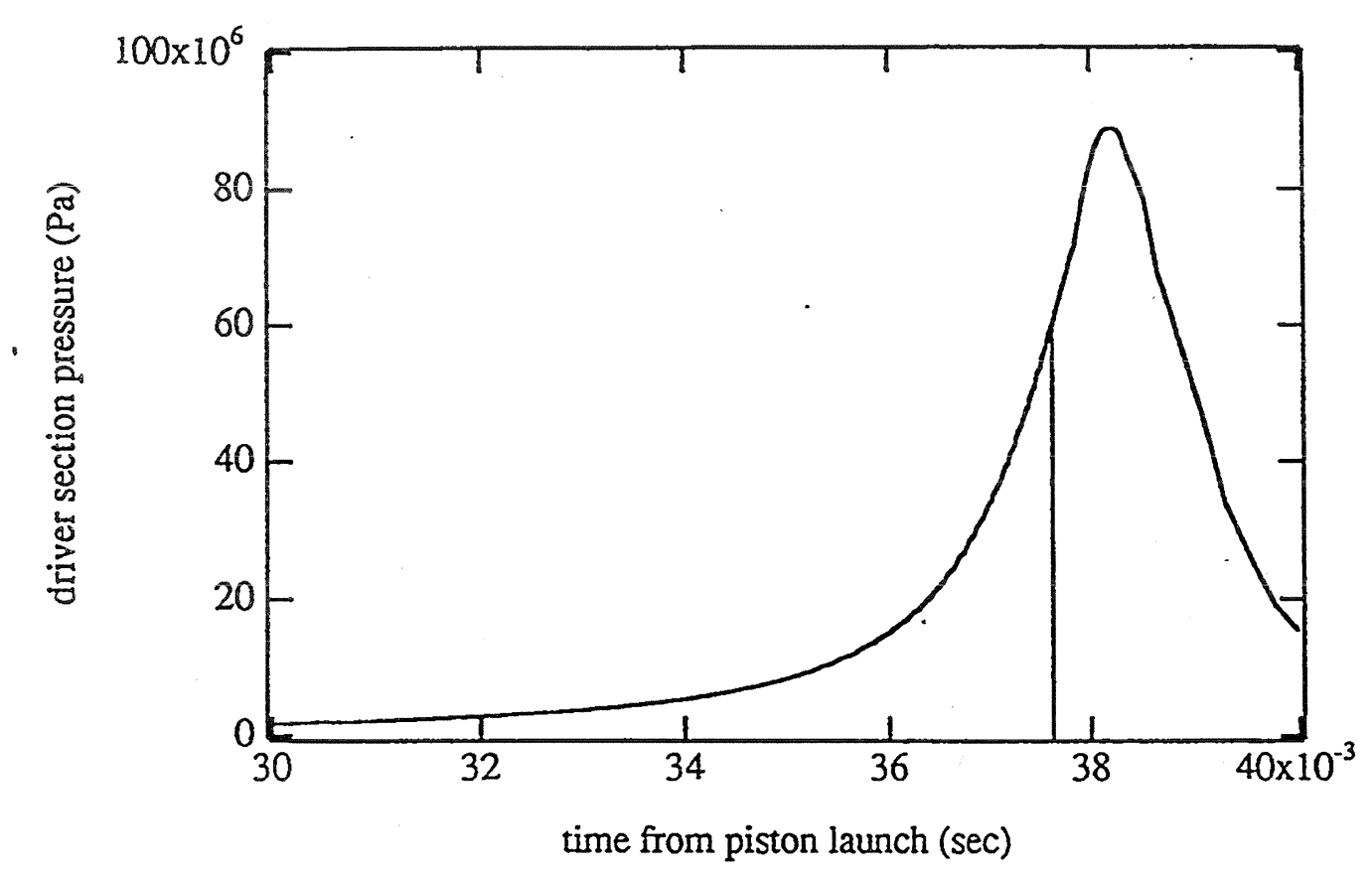

Figure 4b:Predicted helium pressure versus time from piston release just before diaphragm rupture

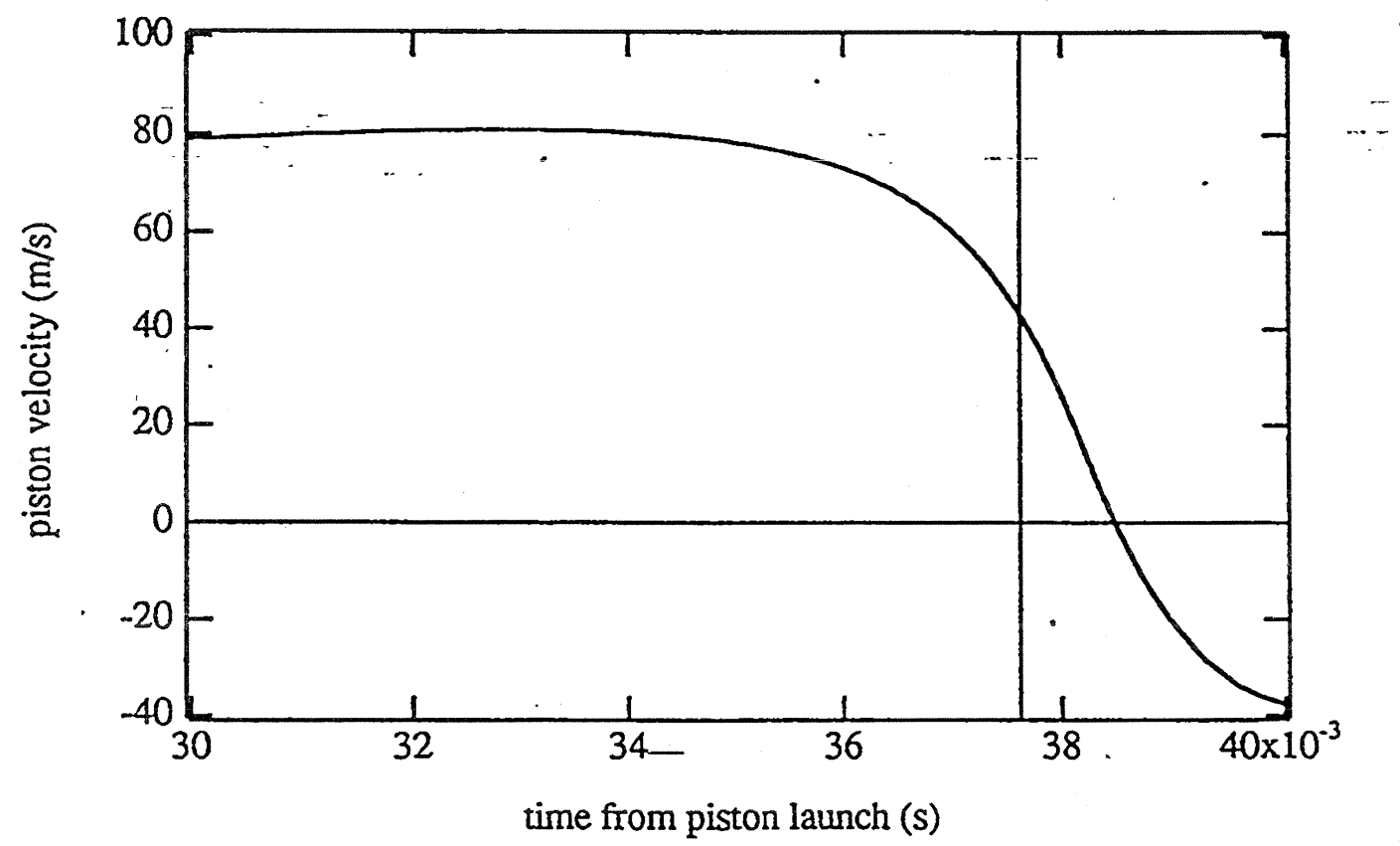

Figure 4a: Predicted piston velocity versus time from piston release just before diaphragm rupture 


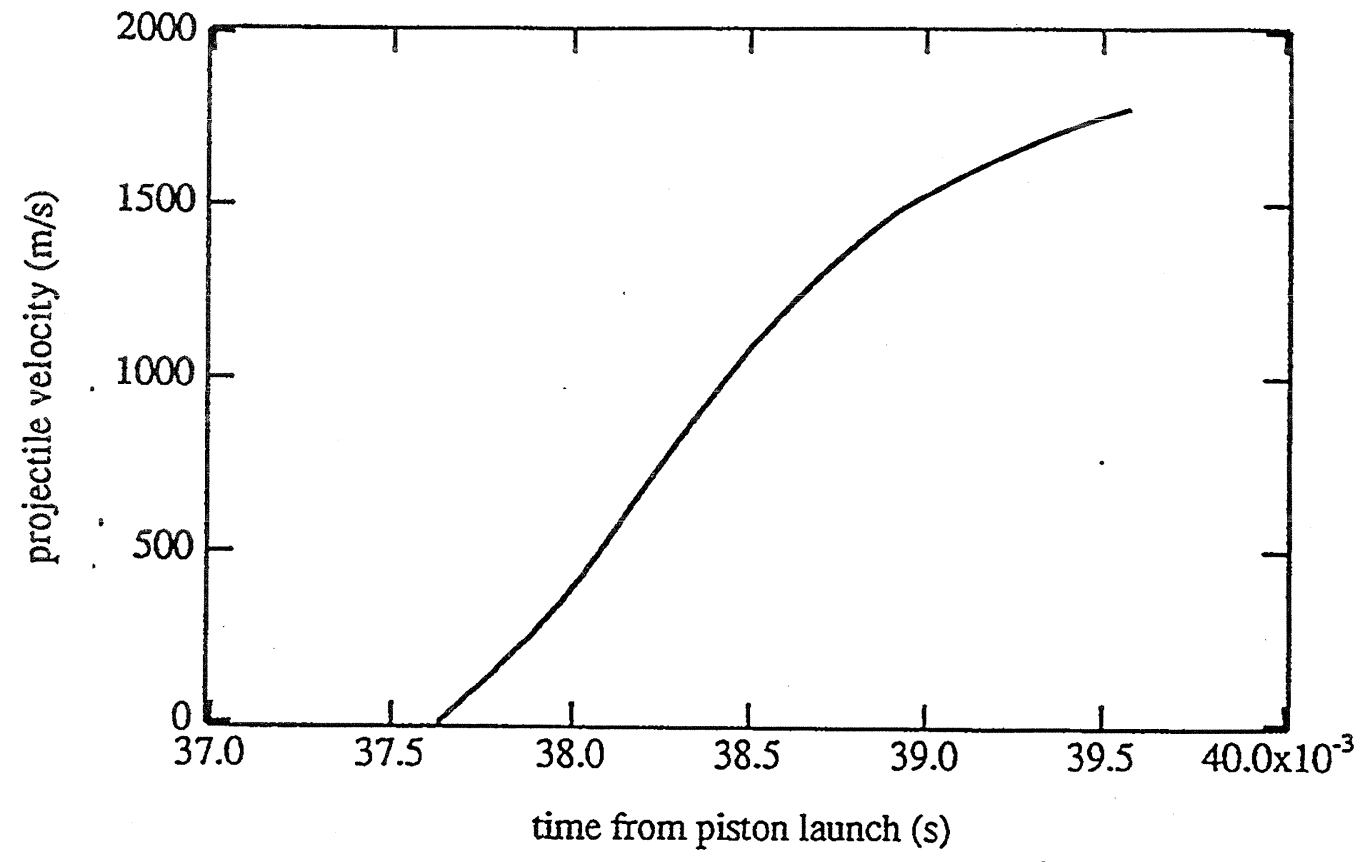

Figure 5b: Predicted projectile velocity versus time from piston release

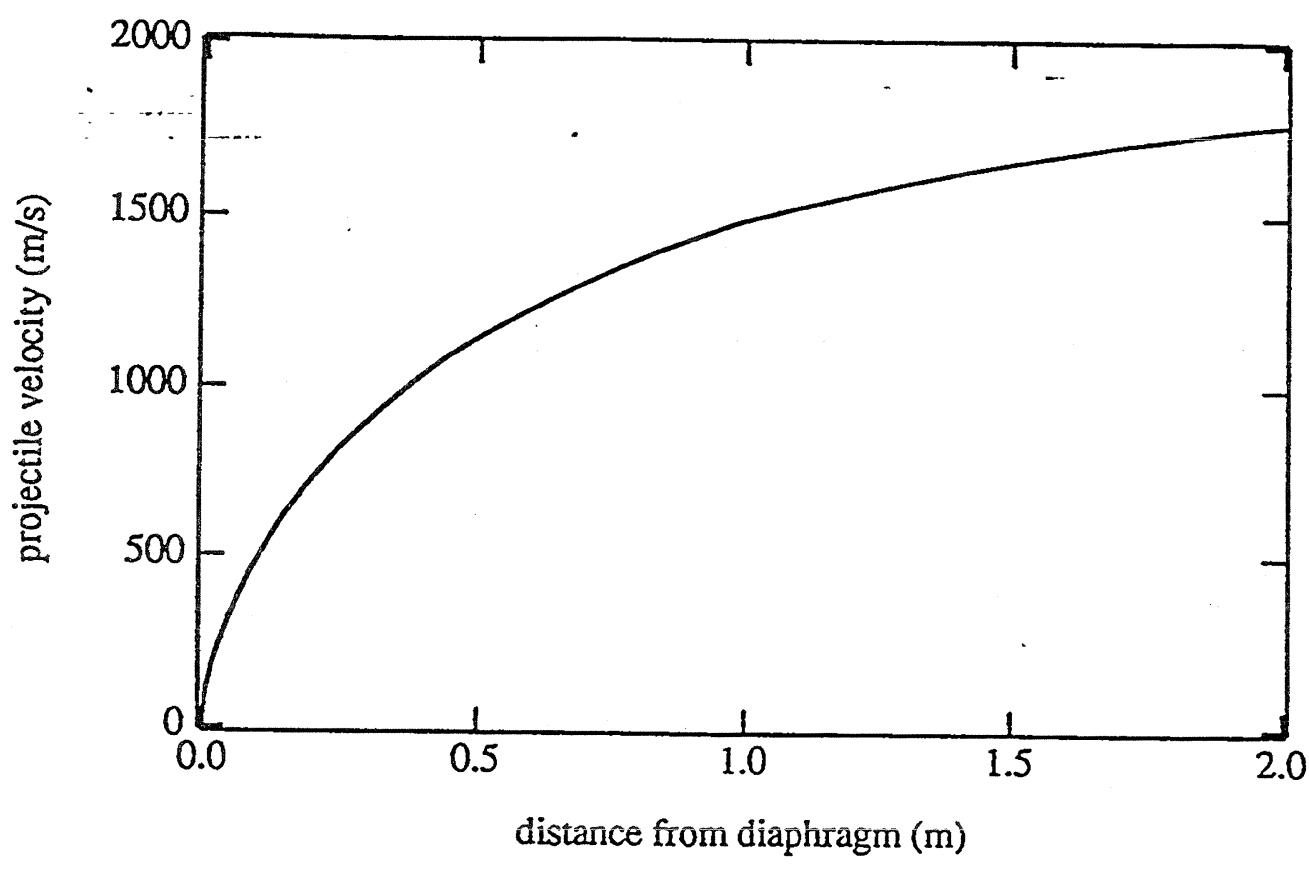

Figure 5a: Predicted projectile velocity versus distance from diaphragm 


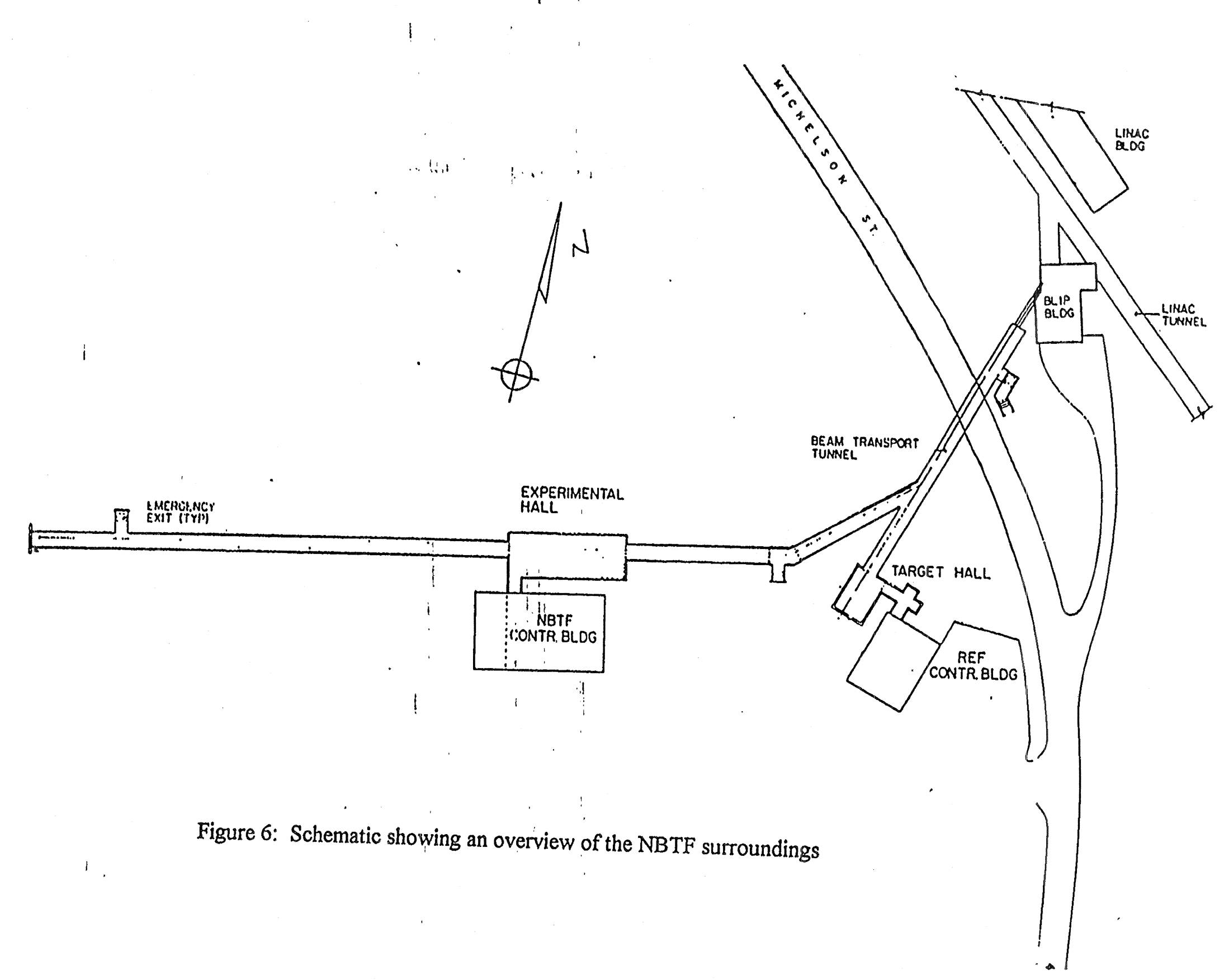




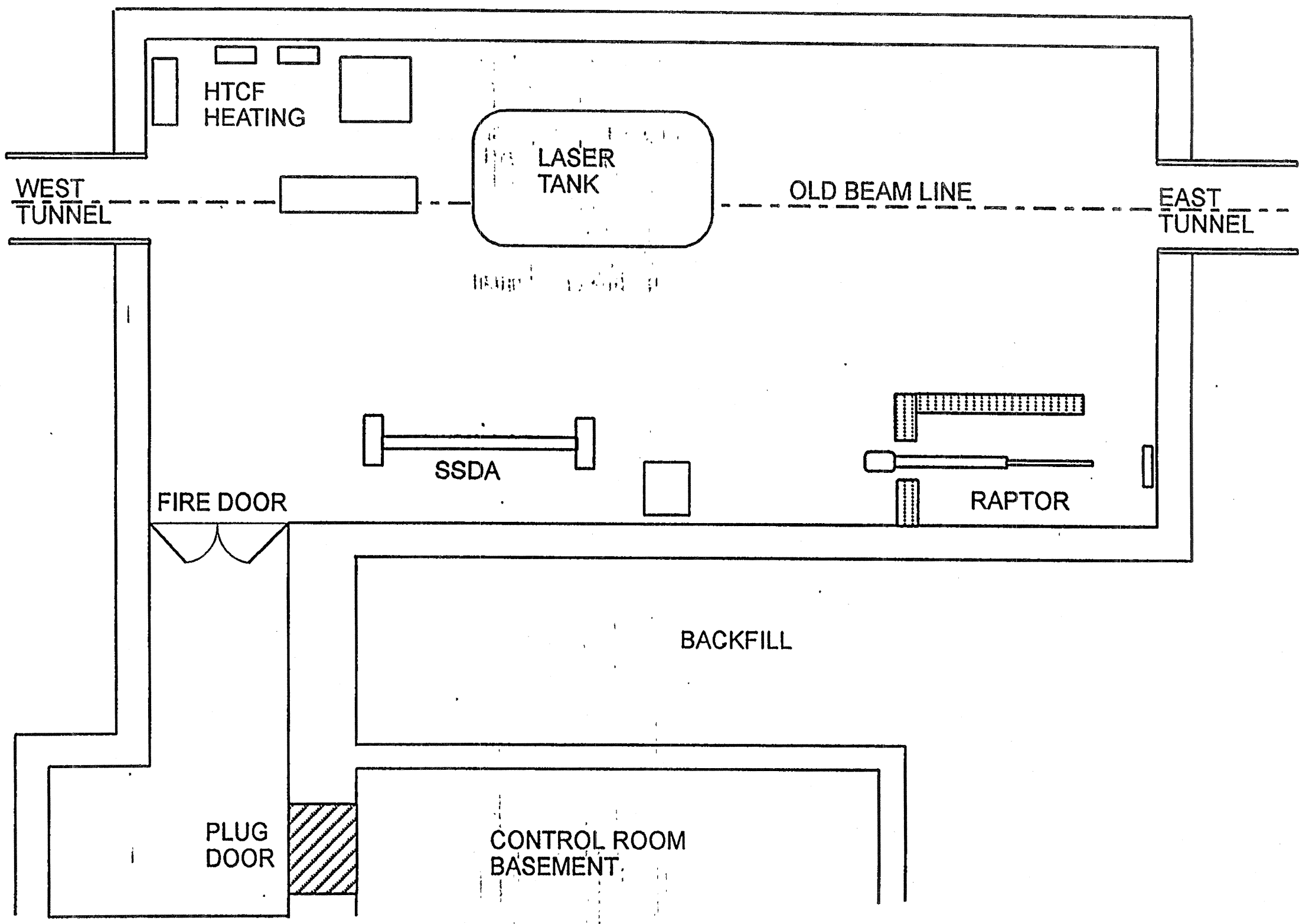

Figure 7: Schematic showing an overview of the Experimental Hall 


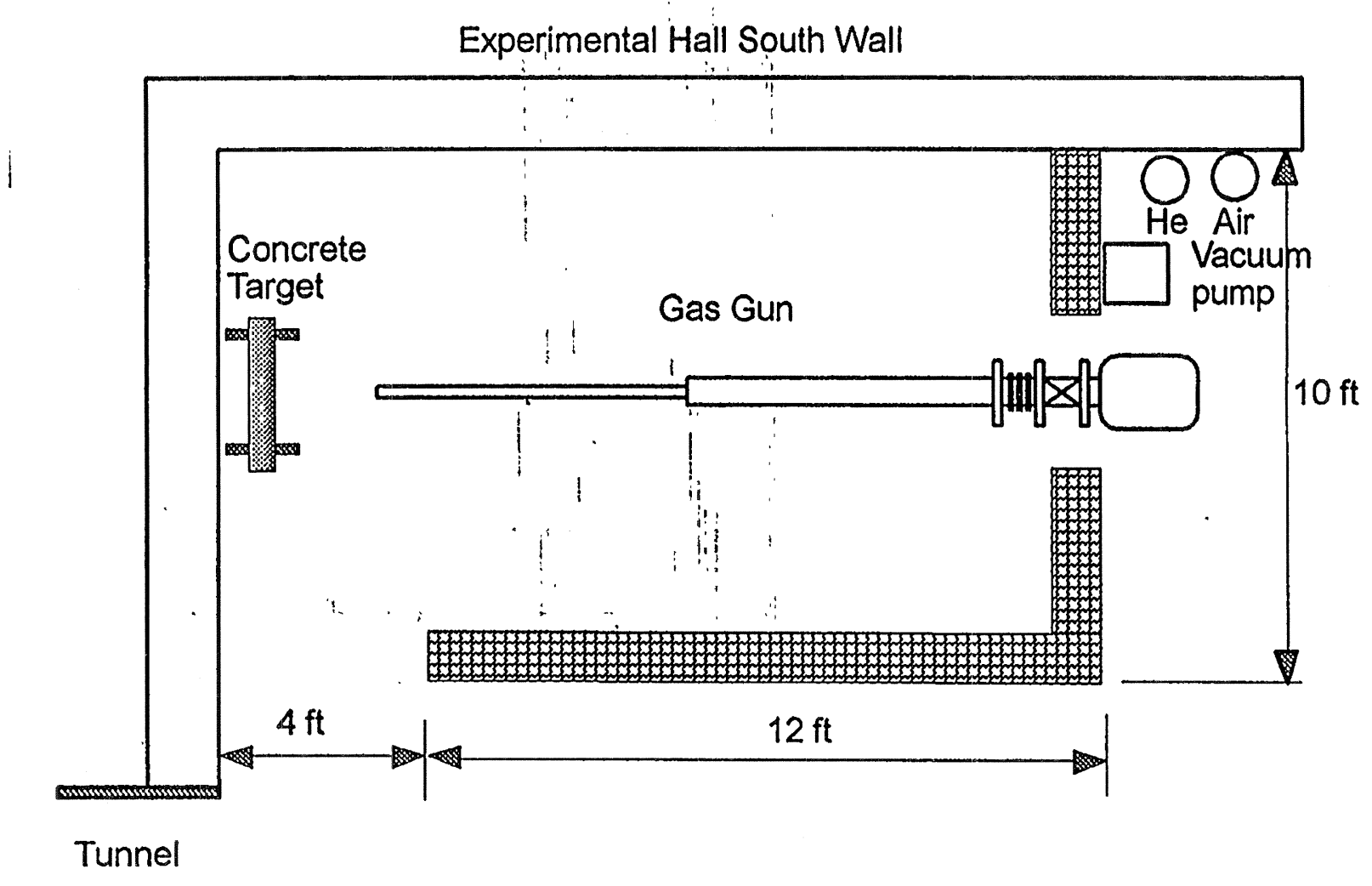

Figure 8: Schematic of experimental room layout

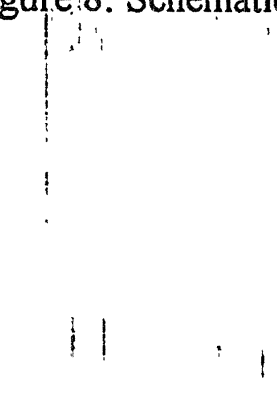




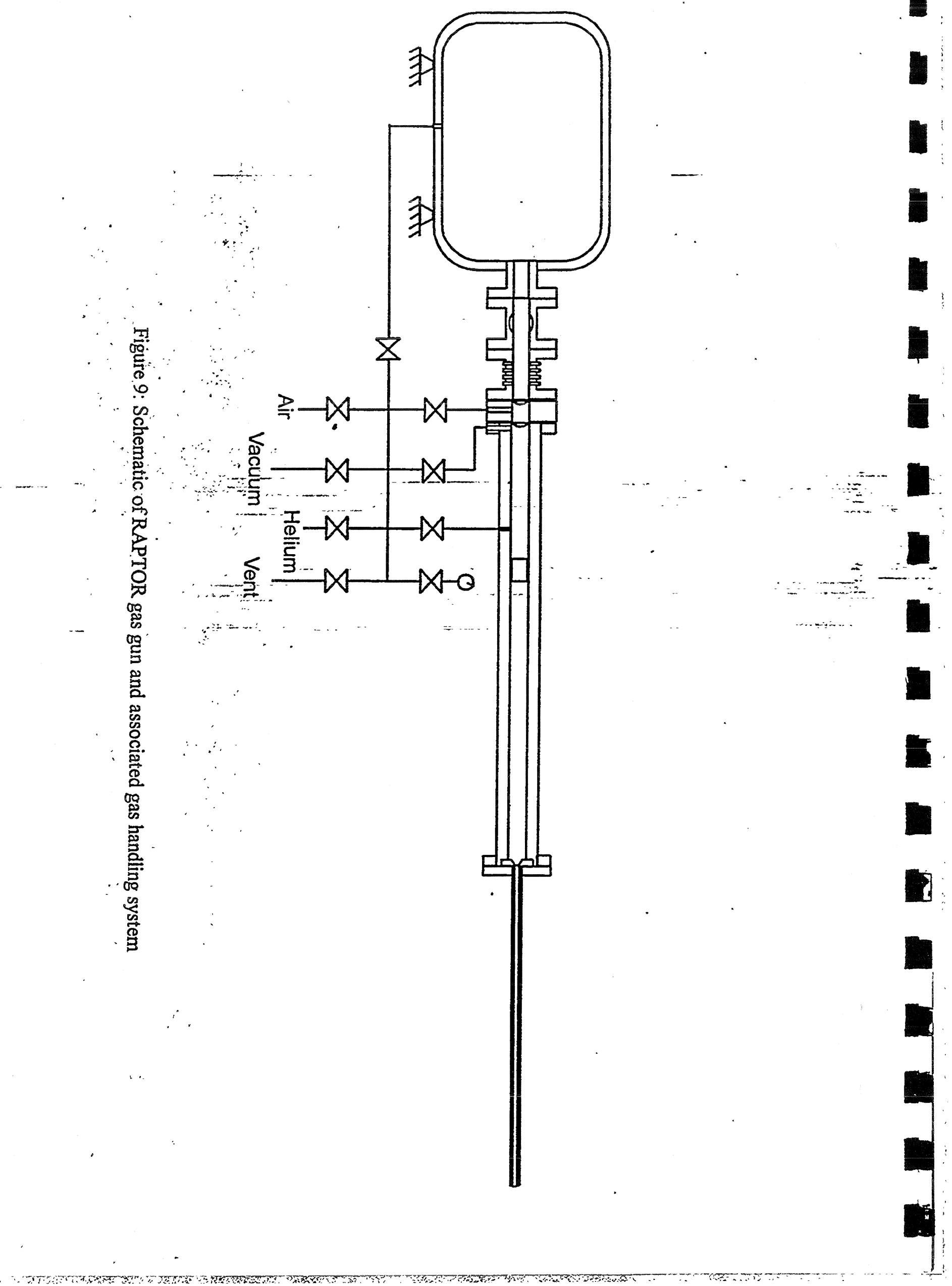



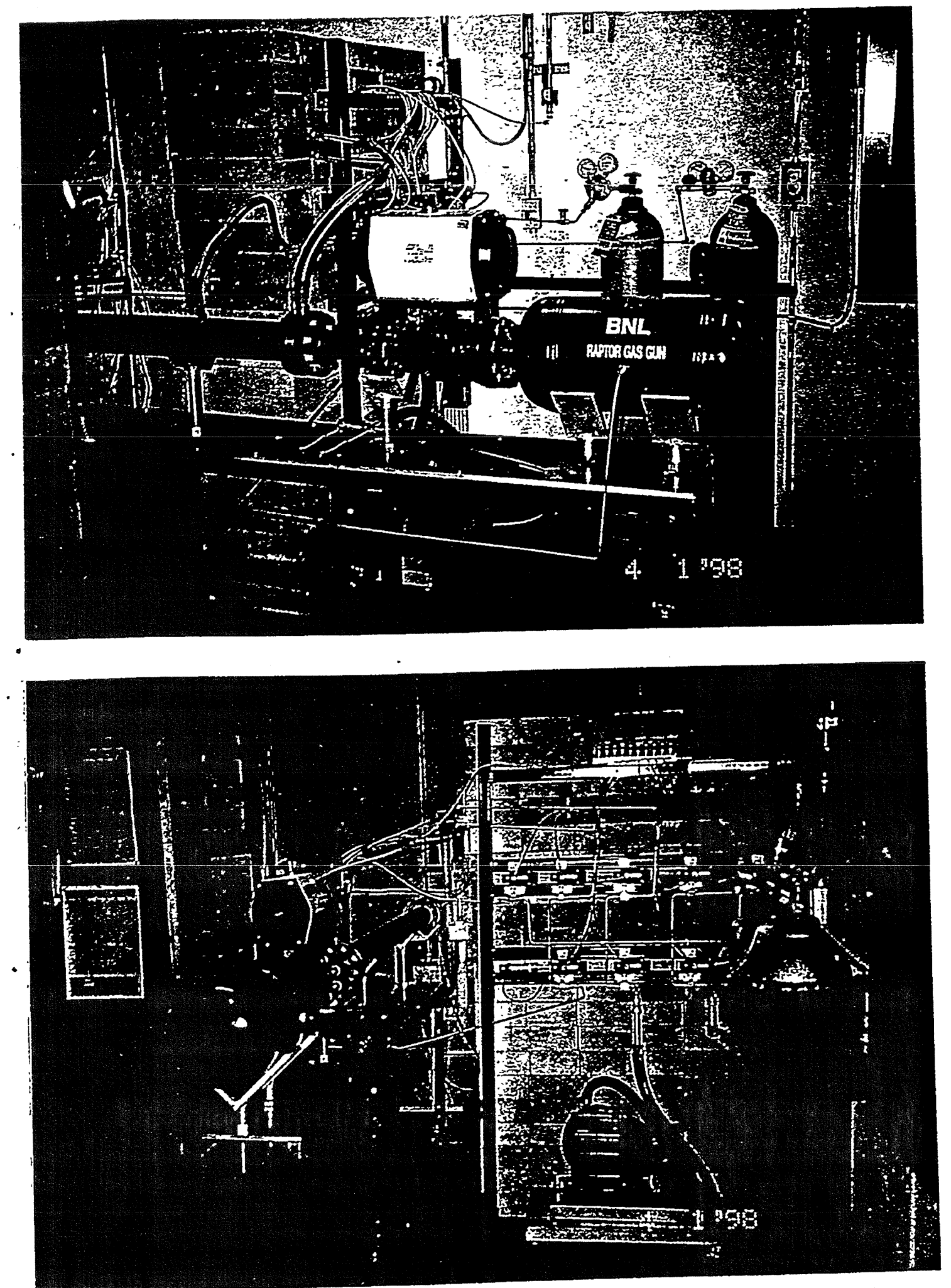

Figure 10: Photographs of the RAPTOR gas gun and gas handling system 


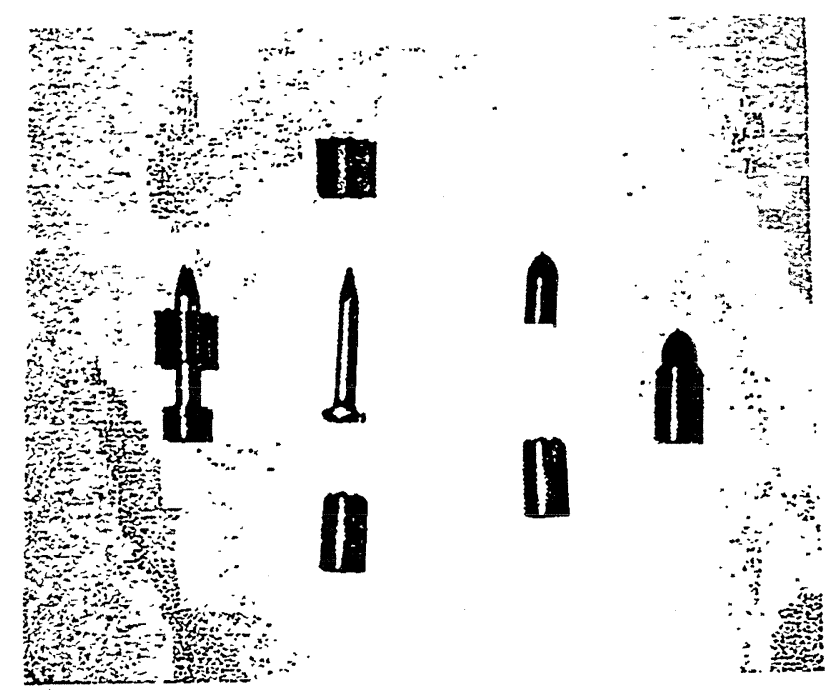

Figure 11: Photographs of two different projectiles and sabot used in the gas gun 


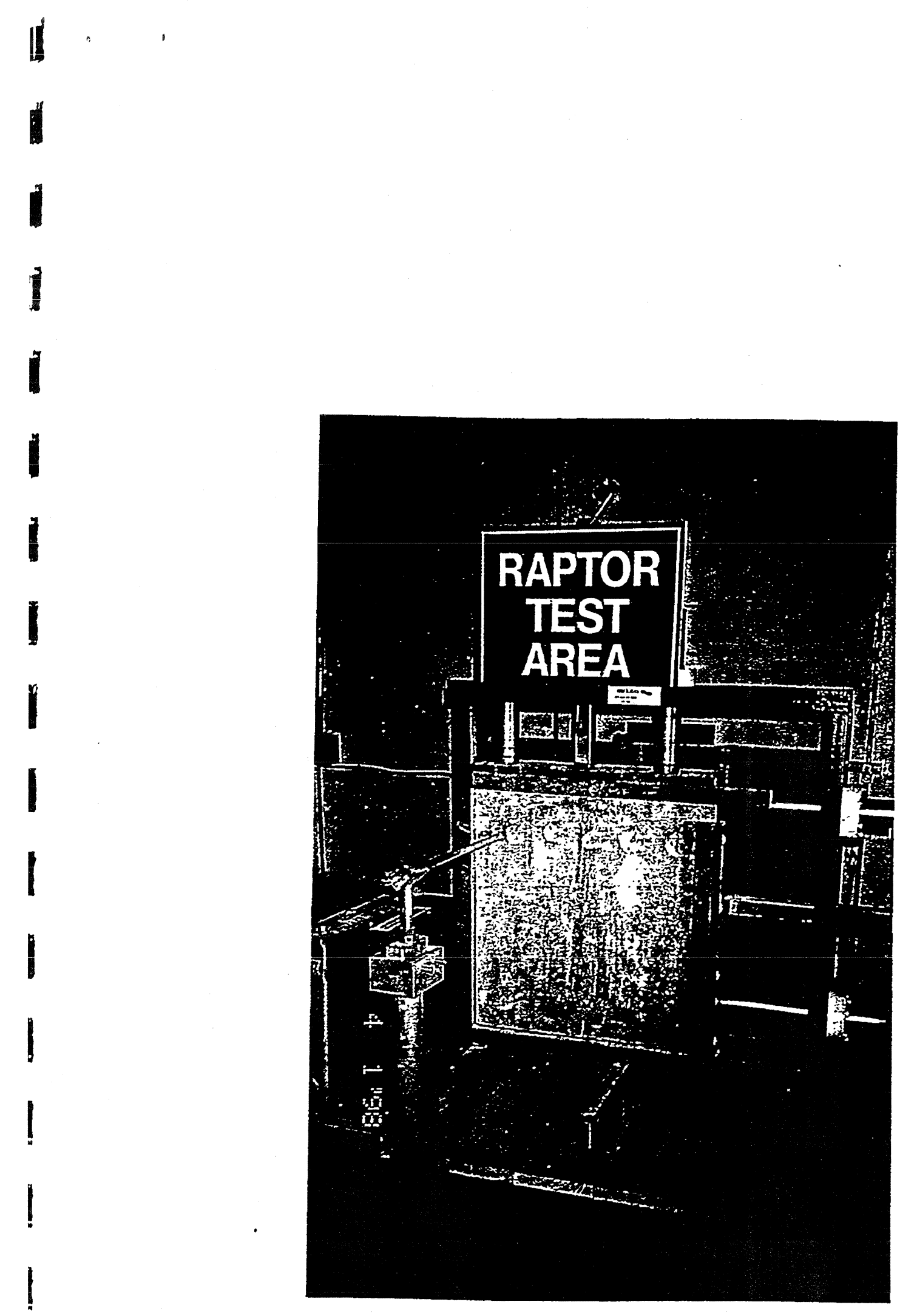

Figure 12: Photograph of the target stand with concrete target in place 


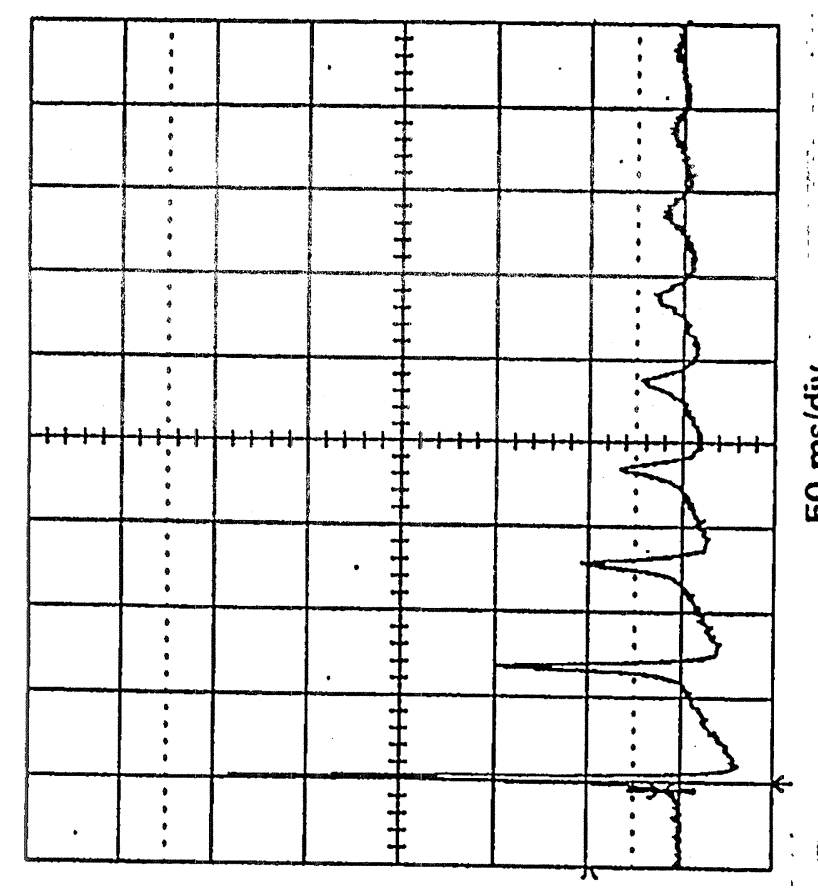

n!p/ssd ZLZL

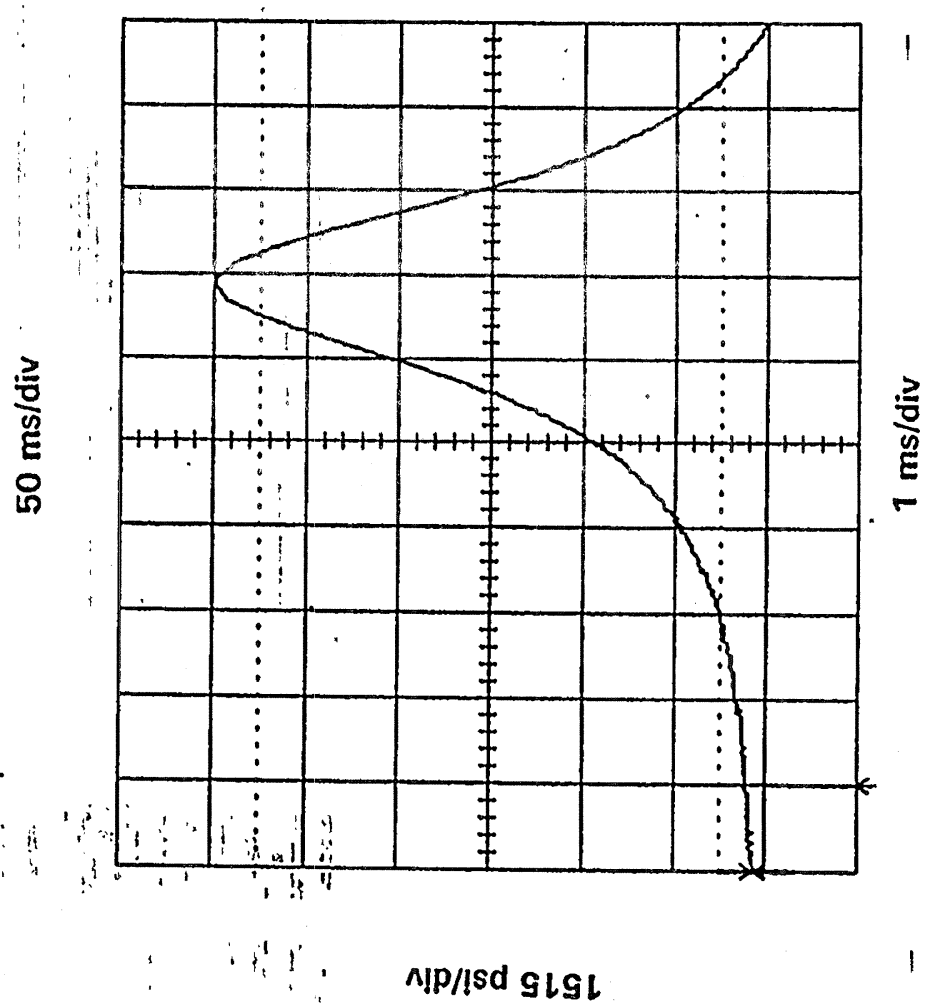

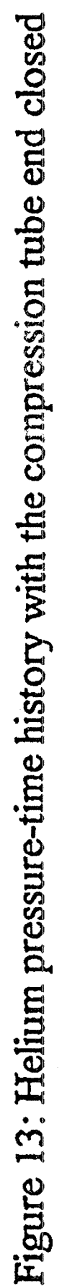

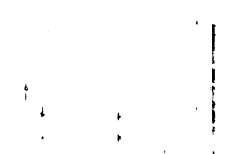




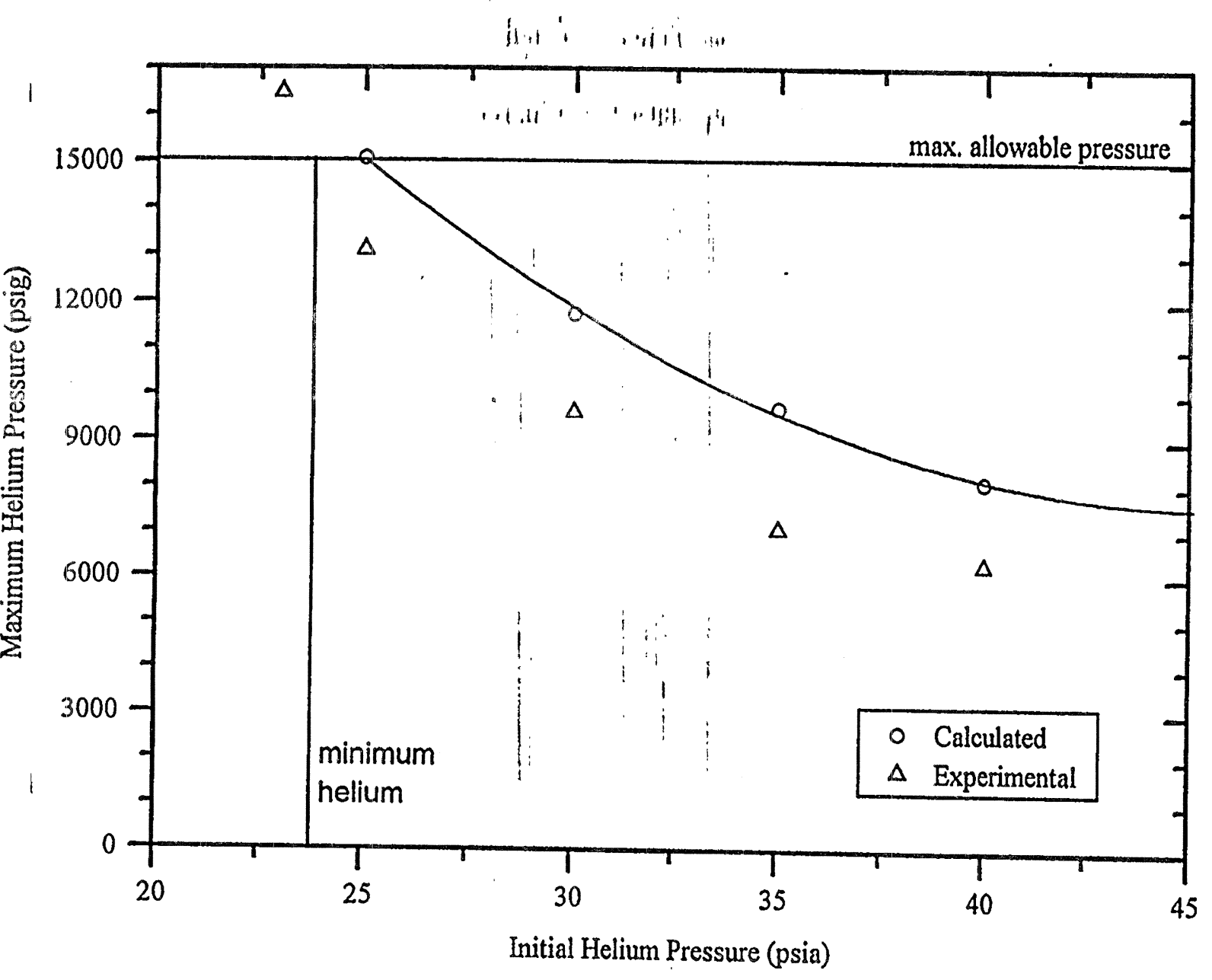

Figure 14: Peak helium pressure versus initial helium pressure with the compression tube end closed 
PT1 PT2

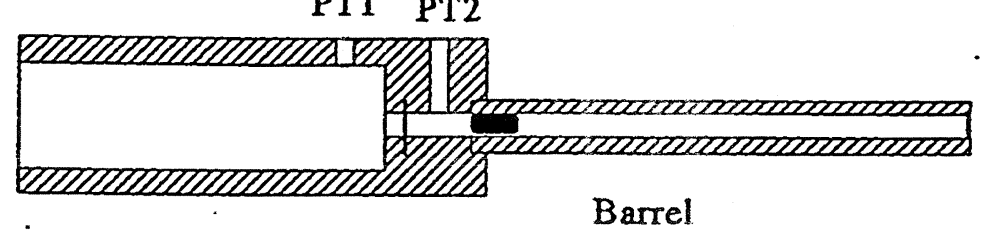

Compression tube

Barrel

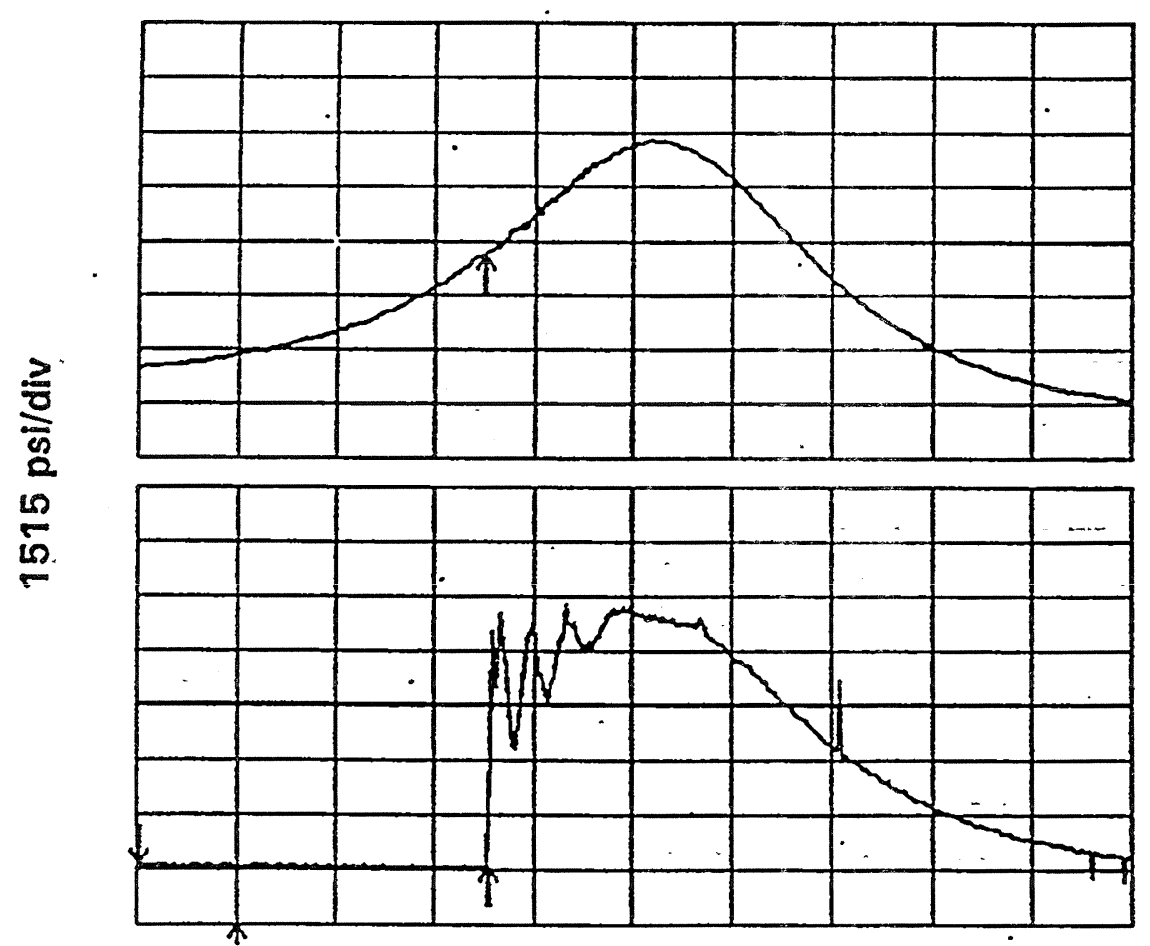

PT1

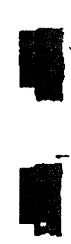

$+\ldots-\ldots$
$+\cdots$
$\cdots+\cdots-\infty$

흘

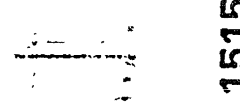

$0.5 \mathrm{~ms} / \mathrm{div}$

PT2

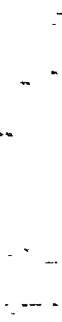

\author{
$0.5 \mathrm{~ms} / \mathrm{div}$
}

Figure 15: Helium pressure-time history measured at locations before and after the diaphragm 

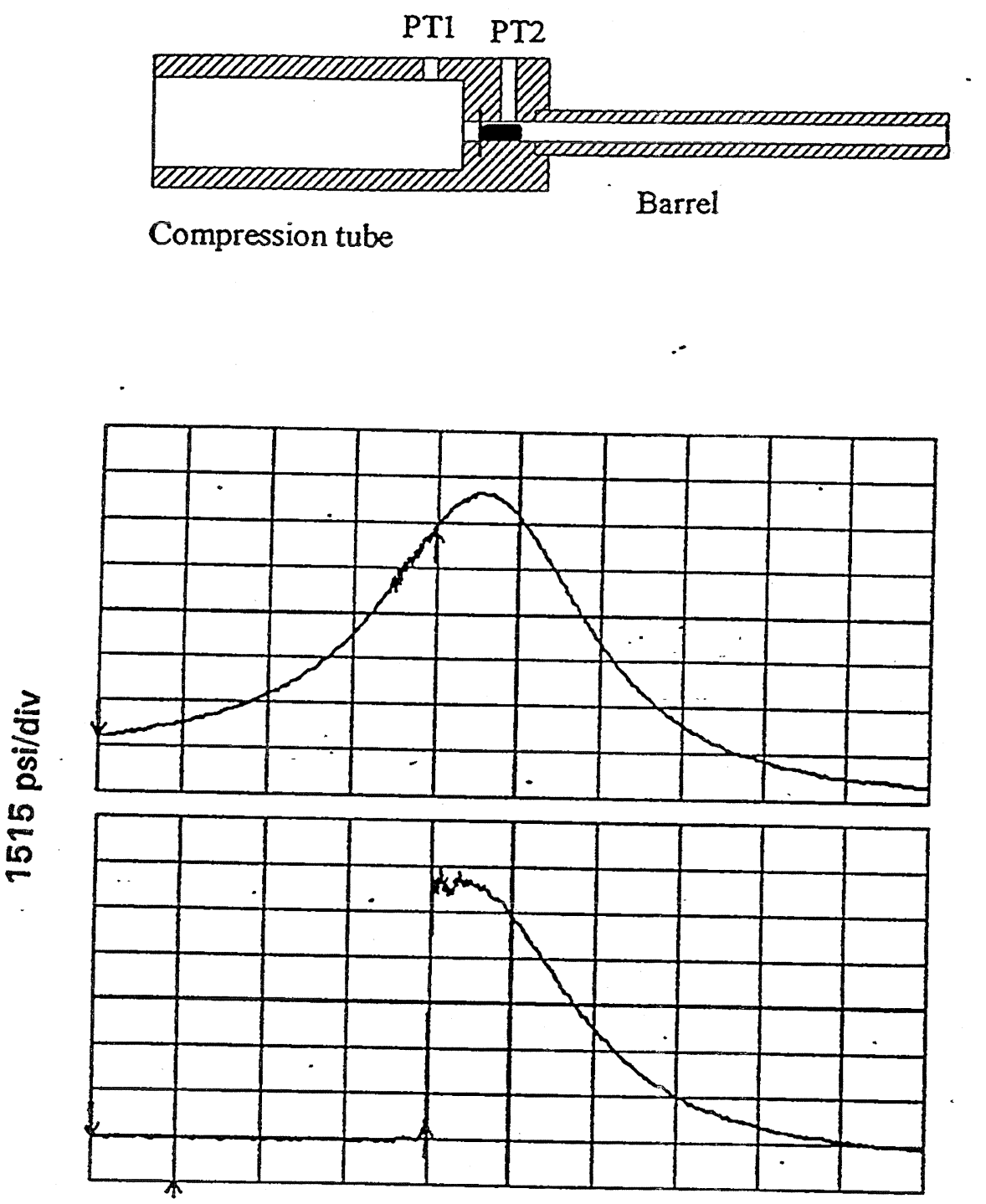

PT1

PT2

\section{$0.5 \mathrm{~ms} / \mathrm{div}$}

Figure 16: Helium pressure-time history measured at locations before and after the diaphragm 


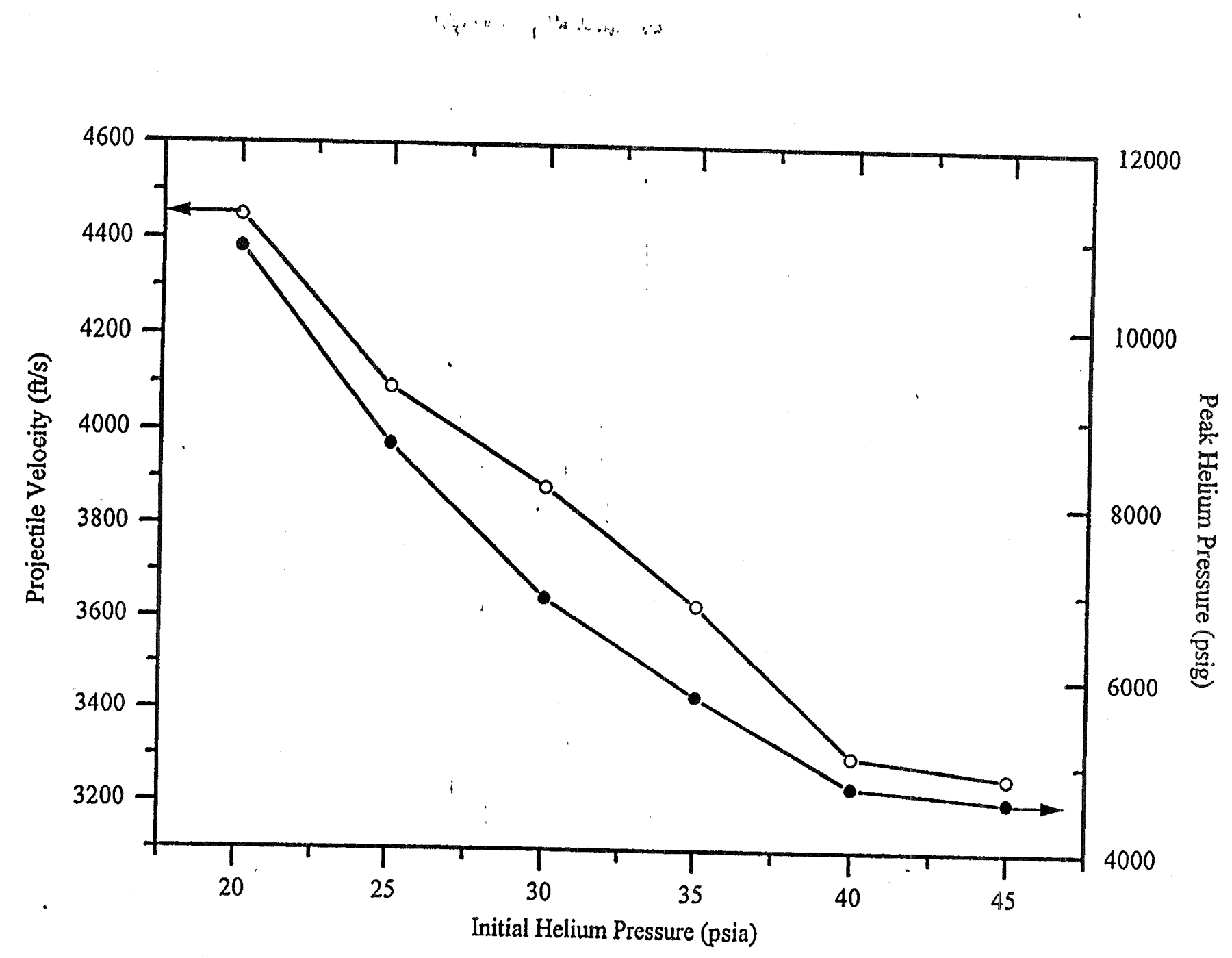

Figure 17: Measurement for $500 \mathrm{psig}$ air and $2.5 \mathrm{~g}$ projectile/sabot 


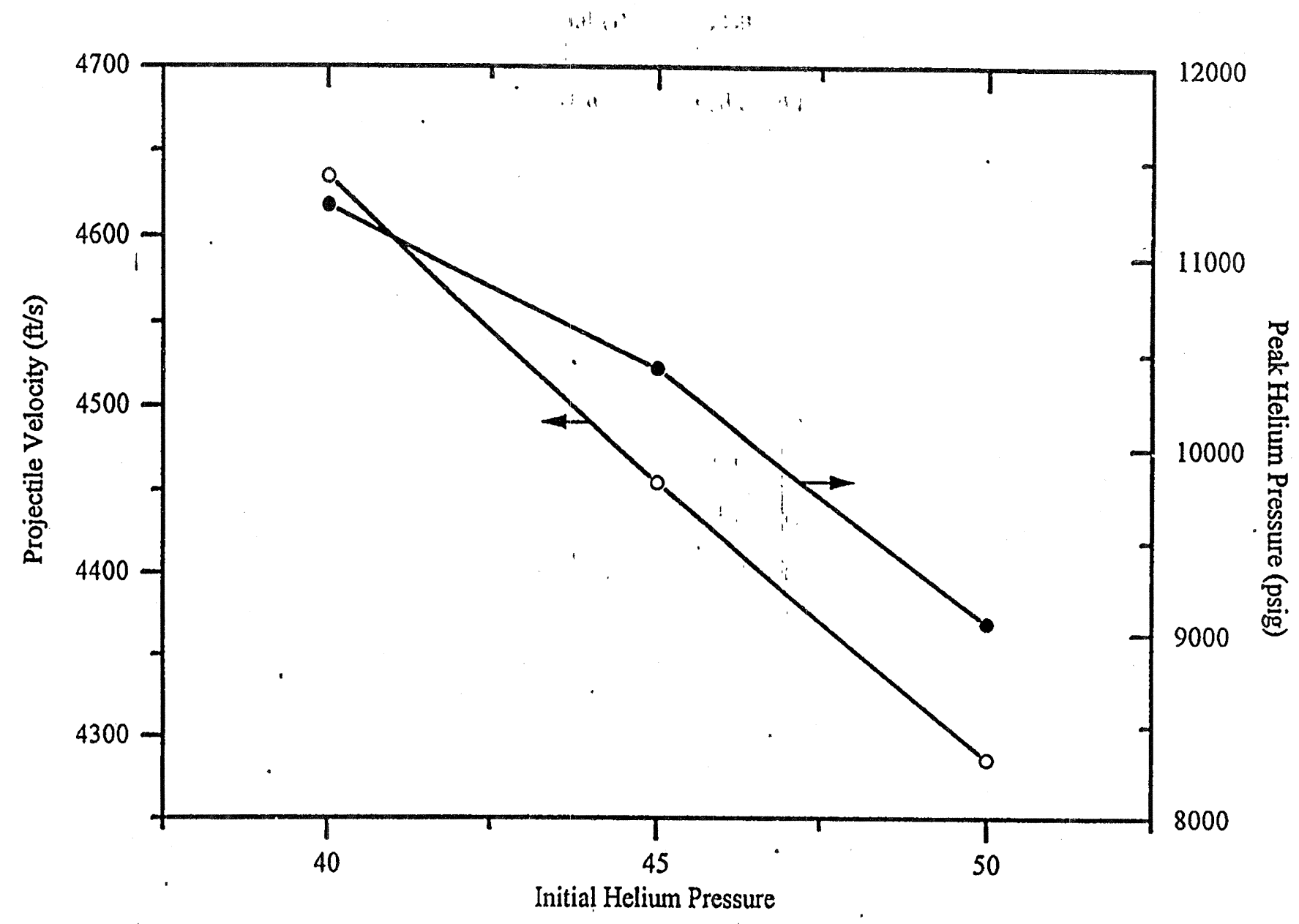

Figure 18: Measurements for $750 \mathrm{psig}$ air and $2.5 \mathrm{~g}$ projectile/sabot 


\begin{tabular}{|cccccc}
\hline 0 & 0 & 0 & 0 & 0 \\
31 & & & & 27 \\
0 & 0 & 0 & 0 & 0 \\
37 & & & & 33 \\
& & & & & \\
& & & & & \\
0 & 0 & 0 & 0 & 0 & 0 \\
38 & & & & & 43 \\
\hline
\end{tabular}

(A) $4^{\prime \prime}$ thick, $0.22 \times 0.59^{\prime \prime}$ proj
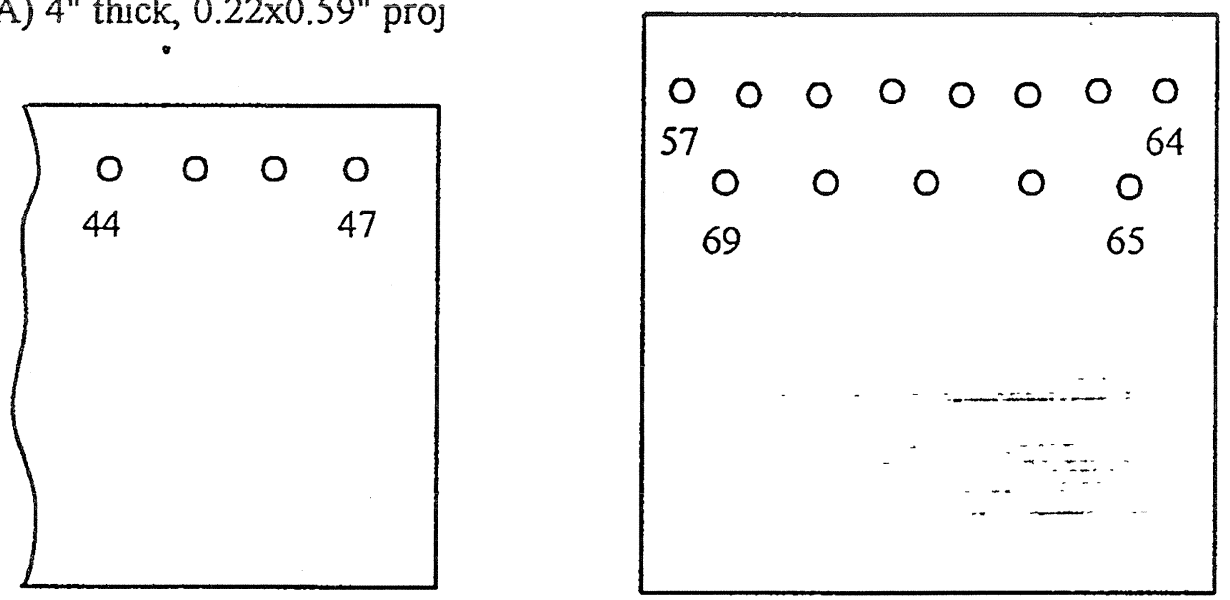

(B) 4" thick, $0.125 \times 1.0^{\prime \prime}$ proj

(C) 6" thick, $0.125 \times 1.0^{\circ 1}$ proj

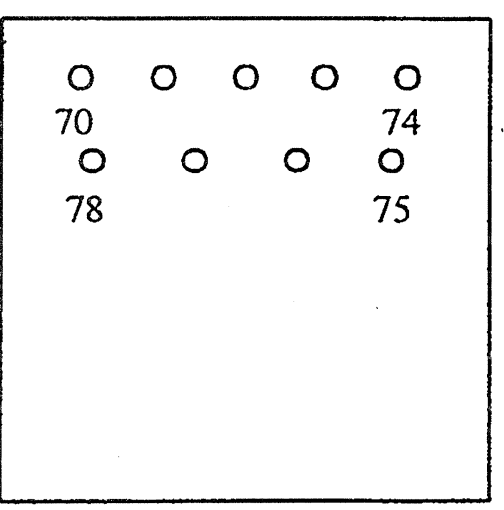

00000

$83 \quad 79$

(D) $4^{\prime \prime}$ thick, $0.125 \times 1.0^{\prime \prime}$ proj

(E) 4"thick/reinf, 0.125xl" proj

Figure 19: Schematic of concrete targets showing impact locations and run numbers 


\begin{tabular}{|c|c|c|c|c|c|}
\hline 0 & 0 & 0 & 0 & & O \\
\hline 2.1 & 1.8 & 1.8 & 1.8 & & 1.5 \\
\hline 0 & 0 & 0 & 0 & & 0 \\
\hline 2.3 & 1.9 & 1.8 & 1.7 & & 2.5 \\
\hline 0 & 0 & 0 & 0 & 0 & 0 \\
\hline 2.1 & 2.4 & 1.4 & 2.0 & 1.9 & 2.5 \\
\hline
\end{tabular}

(A) 4" thick, $0.22 \times 0.59^{\prime \prime}$ proj

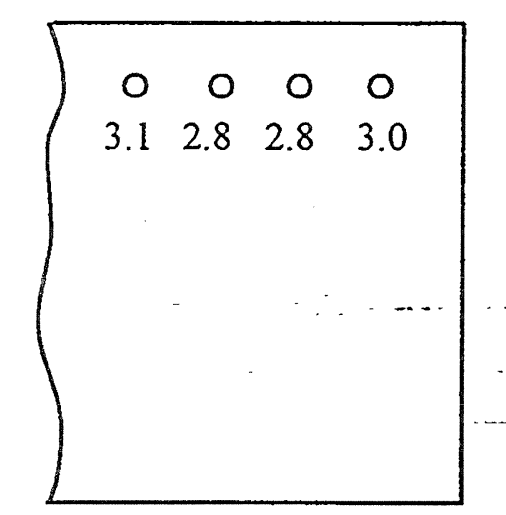

(B) 4" thick, 0.125x1.0" proj....

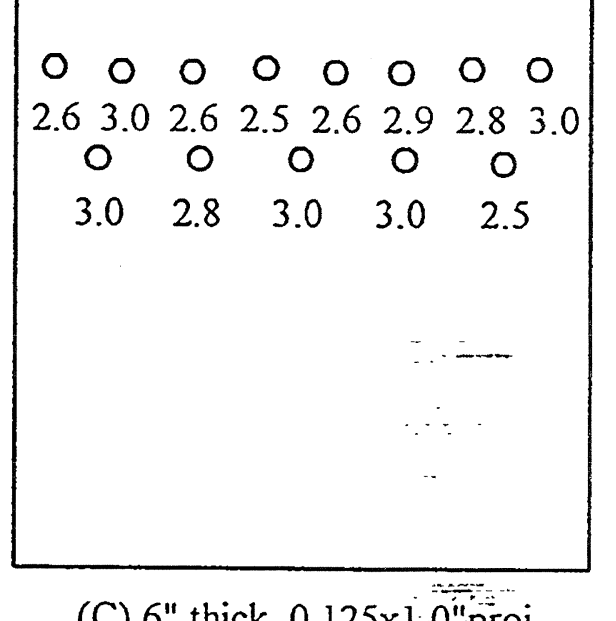

(C) 6" thick, $0.125 \times 1: 0$ "proj

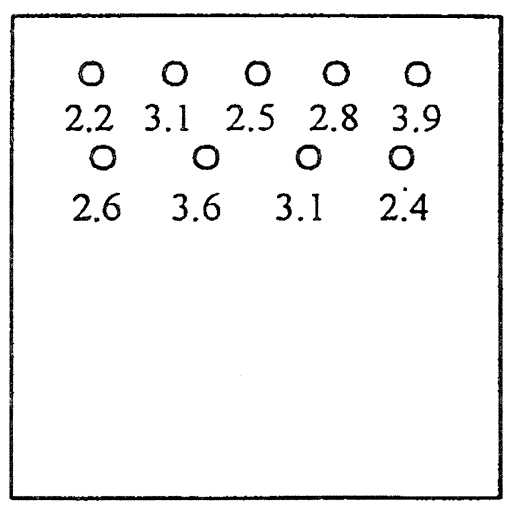

(D) $4^{\prime \prime}$ thick, $0.125 \times 1.0 "$ proj

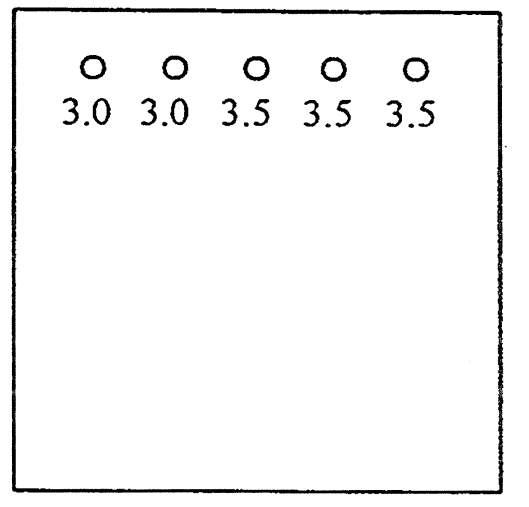

(E) 4 "thick/reinf, $0.125 \times 1$ " proj

Figure 20: Schematic of concrete targets showing impact locations and penetration depths in inches 


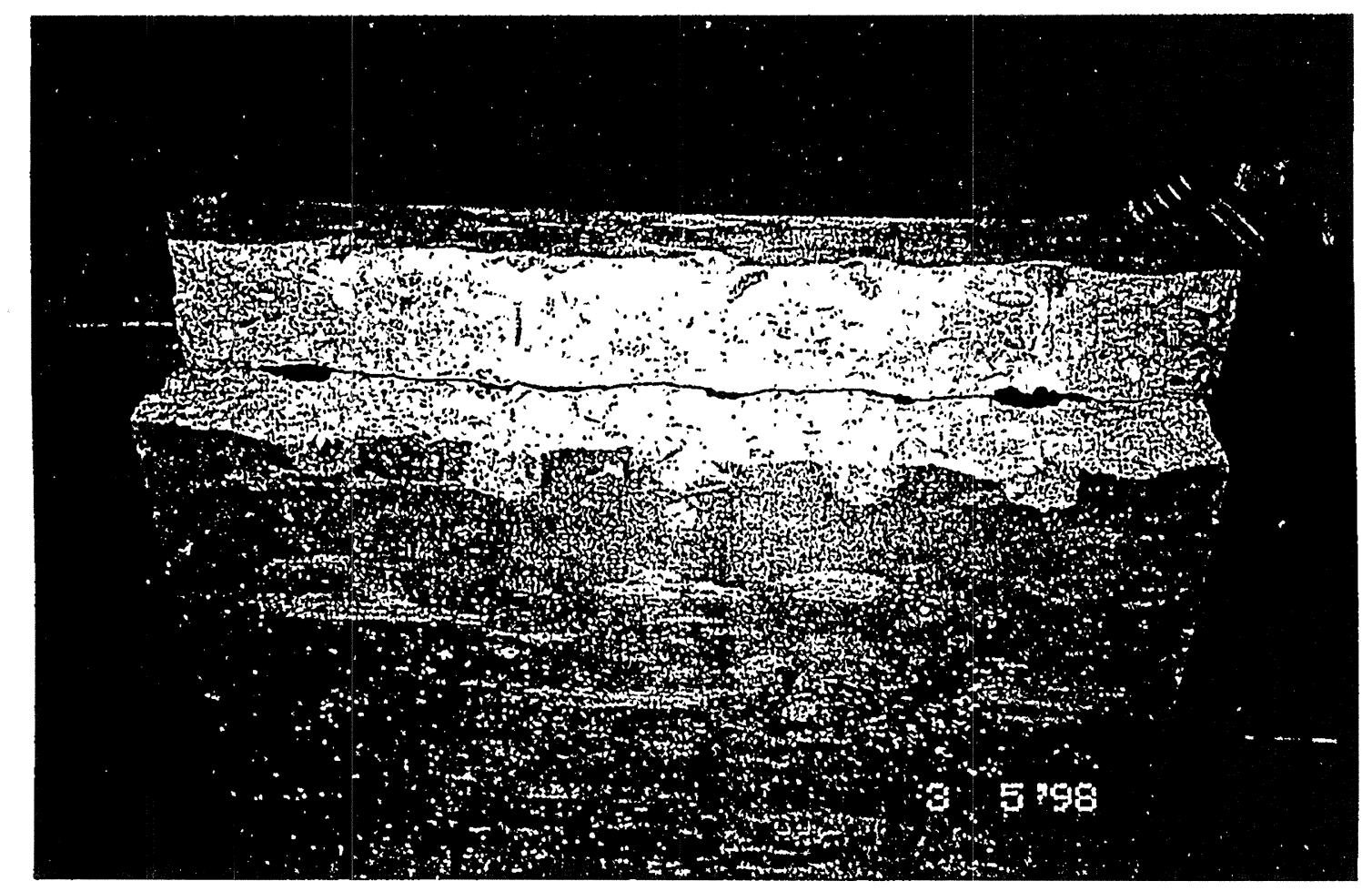

Figure 21. Photograph of cracked 4 " thick concrete target, test series \#70-74 of Figure 19 


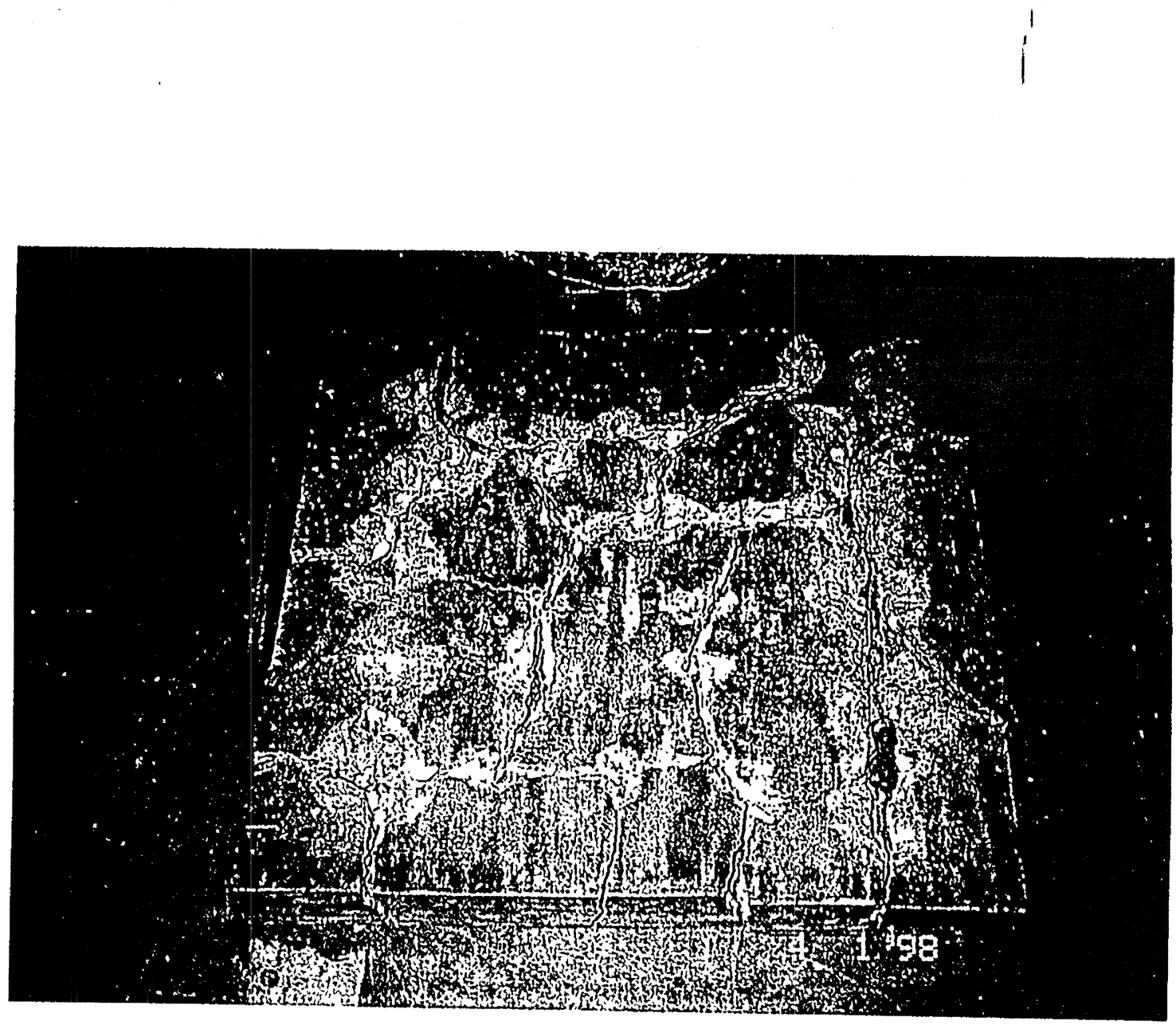

Figure 22: Photogtaph of completely broken up 4"thick concrete target 


\section{APPENDIX A}

\section{Numerical Code for the Design of a Free Piston Gas Gun}




\section{Numerical code PISTON}

Only a brief review and the main equations of the method of characteristics for unsteady section 1.2

\section{1,1 Basic method of characteristics for unsteady one dimensional flows}

The governing equations for the method consist of the unsteady one-dimensional continuity equation (equation 1.1) and momentum equation (equation 1.2).

$$
\begin{gathered}
\frac{\partial \rho}{\partial t}+\frac{\partial(\rho u)}{\partial x}=0 \\
\rho \frac{\partial u}{\partial t}+\rho u \frac{\partial u}{\partial x}+\frac{\partial p}{\partial x}=0
\end{gathered}
$$
Assuming the flow to be isentropic $(\mathrm{ds}=0$ ), it can be shown that the compatibility
equations (equation 1.3) hold along paths called characteristic lines (equation 1.4)

$$
\begin{aligned}
& d u \pm \frac{d p}{\rho a}=0 \\
& \frac{d x}{d t}=u \pm a
\end{aligned}
$$

Where the speed of sound a, is defined by equation 1.5

$$
a=\sqrt{\left(\frac{\partial p}{\partial p}\right)_{s}}
$$
Also only using the fact that the flow is isentropic, we can derive equation 1.6 for the
case of calorically perfect gas.

$$
\frac{d p}{p}=\frac{2 a}{\gamma-1} d a
$$

Substituting equation 1.6 in equation 1.3 and integrating along the characteristic lines we
get

$$
\begin{aligned}
& F_{+}=u+\frac{2 a}{\gamma-1}=\text { constant (along plus characicristic) } \\
& F_{-}=u-\frac{2 a}{\gamma-1}=\text { constant (along minus characteristic) }
\end{aligned}
$$
Solving these two equations, for the intersection point of a plus characteristic and a minus
characteristic, gives

$$
u=\frac{1}{2}\left(F_{+}-F_{-}\right)
$$




$$
a=\frac{\gamma-1}{4}\left(F_{+}-F_{-}\right)
$$

There results are summarized in figure 1.1 .

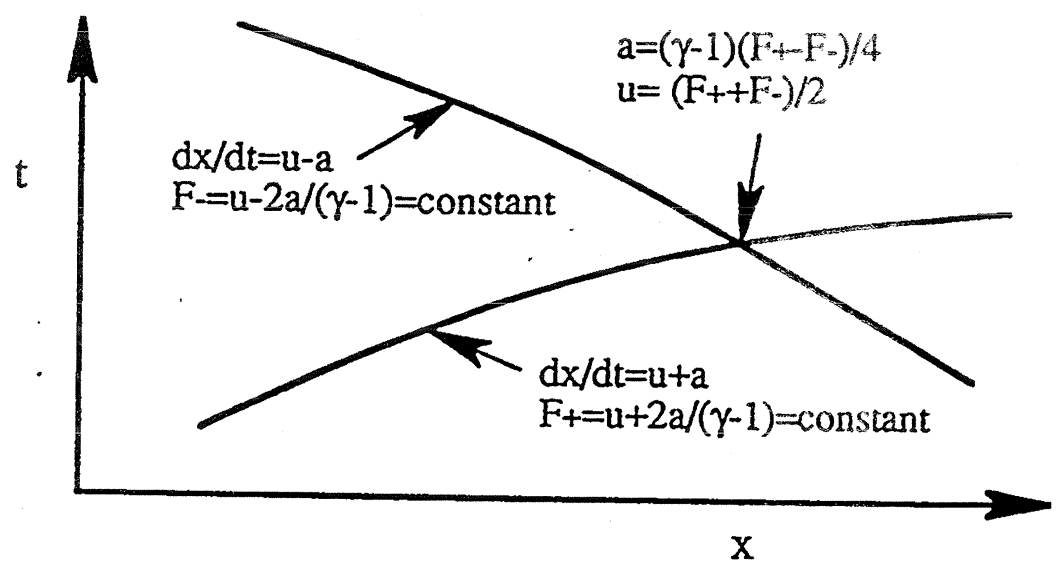

Figure 1.1 Illustration of the characteristic lines in the $x$-t plane.

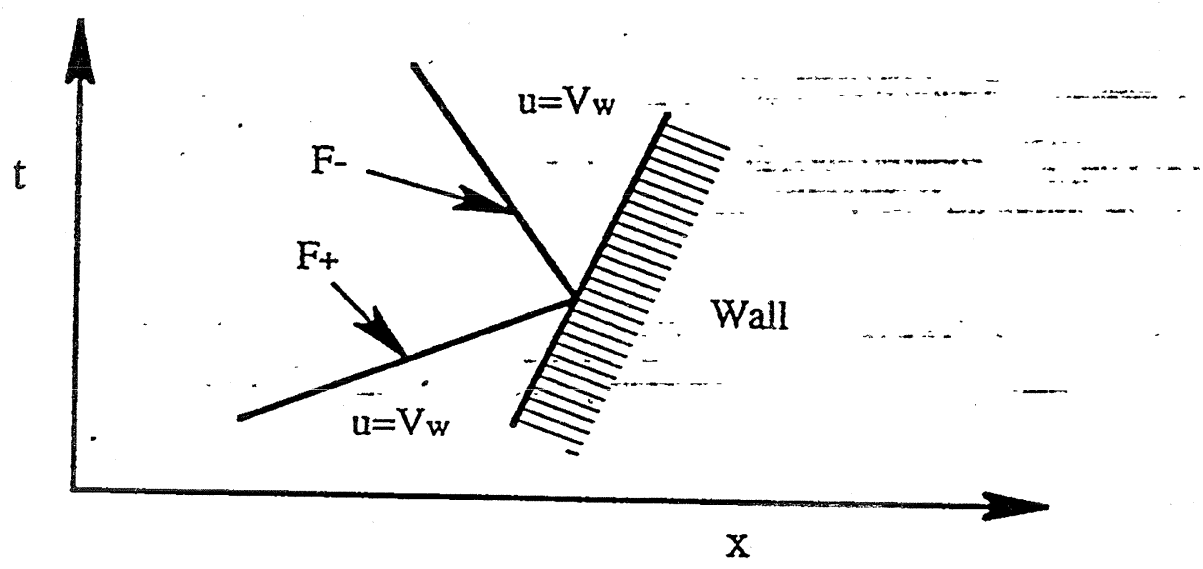

Figure 1.2 Intersection of a characteristic line and a wall.

In the case of the intersection of a plus characteristic line with the piston (or projectile), as in figure 1.2 , we know that a minus characteristic will be created. Using equation 1.9 , with $u=V_{w}$, we can determine $F_{-}$. Then using equation 1.10 we can determined $a$, the speed of sound at the intersection point. An interaction between a minus characteristic and the piston is handled the same way. 


\subsection{PISTON}

Only the conditions in region 4 and 7 are involved in this part of the two-stage light-gas gun flow simulation. These flow conditions affect the dynamics of the piston. Both the compressed air in region 7 and the helium in region 4 can be considered calorically perfect in this case. In the numerical code, the diameter of the compressed air reservoir is the same as the driver section diameter. Its length is a variable defined in the input file of the program.

The motion of the piston is represented by equation 1.11. The code can take into account friction losses due to both the front sealing ring $f_{f}$ and the back sealing ring $f_{b}$ on the piston. It can also take into account pressure losses due to the boundary layer in the compressed air section $\left(f_{v}\right)$ in region 7 . It is possible to represent the friction loses due to the sealing rings in a form of a friction coefficient because they are proportional to the pressure applied on the rings. These friction coefficients also include some geometrical dimensions.

Comparisons with actual tests in the free piston shock tunnel T5 at Caltech have set the values of $f_{b}$ and $f_{f}$ to be between 0.02 and 0.04 depending on the initial test conditions. These friction loses amount for only about $2 \%$ in the reduction of the piston acceleration. Better sealing rings design in the free-piston shock tunnel HEG in Germany have shown friction coefficient twice as small, making the friction loses practically negligible. In the case of the viscous loses the pressure drop is proportional to the length of the tube or more precisely proportional to $L / D$ (see Mirels ${ }^{1}$ ). In the case of T5, LD is 100 and the pressure drop coefficient $\left(f_{v}\right)$ is about 0.05 . In the case of the two-stage light-gas gun

-1 look at in section 3 , the L/D of the driver section is only 36 . It makes the viscous loses in the light-gas gun only about $35 \%$ the value found in T5. The overall acceleration losses

$\because .$. in the two-stage light-gas gun will certainly be less than the 5\% found in.T5. Even if it is

$\because .$. The case; $;$ it would be easily corrected by increasing the initial air pressure in the compressed air section by $5 \%$ or so.

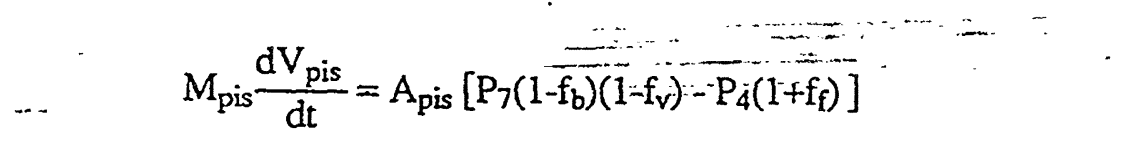

In the numerical code, $\mathrm{dt}$ is taken as the time elapse since the last time a characteristic wave reached the piston. $\mathrm{P}_{4}$ and $\mathrm{P}_{7}$ are also taken from the last interaction of the piston with a characteristic wave. Once the new piston position and velocity are determined, a plus characteristic in region 4 and a minus characteristic in region 7 are created. The

- computation stops when the pressure in region 4 near the diaphragm reaches the preset diaphragm burst pressure.

\footnotetext{
'Mirels, H.; "Shock Tube Test Time Limitation Due to Turbulent Wall Boundary Layer," · Aerospace Corporation Report No. TDR-169 (3230-12) TR-3, May 1963.
} 


\section{Numerical code PROJECTILE}

This section give an overview of the numerical code PROJECTILE. The presentation of the computation method is divided in 3 parts. First, the equations related to the projectile trajectory will be presented. The issues concerning the gun section/driver section transition and computation approach will follow. The last part of the section will examine the piston dynamics which is approach differently compared to the numerical code PISTON.

\subsection{Projectile dynamics}

The equation of motion of the projectile is shown in equation 2.1. Compared to equation 1.11 used in PISTON, the friction coefficient $f_{f}$ has been neglected here because $P_{3}$ is always much larger than $P_{1}$. The fact that the projectile doesn't have actual sealing rings means that the friction must be proportional to the maximum pressure applied on it which is always the back pressure $P_{3}$.

$$
M_{\text {pro }} \frac{d V_{\text {pro }}}{d t}=A_{\text {pro }}\left[P_{3}\left(1-f_{b}\right)\left(1-f_{v}\right)-P_{1}\right]
$$

The pressure $P_{3}$ near the projectile is determined by the computation of the characteristic Waves traveling in region 3 . dt is taken as the time elapse since the last_time a characteristic reached the projectile. $P_{1}$ is determined using the normal shock wave equations described next. The reason why it is possible to used those equations is simple. A small compression wave $(M=1)$ in front of the projectile would take $6 \mathrm{~ms}(2 \mathrm{~m} / 330$ $\mathrm{m} / \mathrm{s}$ ) to exit the gun but the projectile takes only about $2 \mathrm{~ms}$ (see section 3)...This means that the projectile catches up with the compression waves formed during the acceleration.

-These-waves will combine to form a normal shock wave in front of the projectile that can be described by the regular shock wave equations.

If you define the velocity $u_{1}$ as the flow velocity behind a stationary shock wave where the incoming gas flow is W, then it is possible to write

or in a nondimentional form

$$
\mathrm{V}_{\text {pro }}=\mathrm{W}-\mathrm{u}_{1}
$$

$$
\frac{V_{\text {pro }}}{a_{\text {atm }}}=M-M_{1} \frac{a_{1}}{a_{\text {atm }}} \text {. }
$$

Using the basic normal shock waves equations for $M_{1}$ and $a_{1} / a_{a t m}$, equation 2.3 can be presented in the following quadratic equation form with respect to $M$

$$
\mathrm{M}^{2}-\frac{(\gamma+1)}{2} \frac{\mathrm{V}_{\text {pro }}}{\mathrm{a}_{\mathrm{atm}}} \mathrm{M}+1=0
$$

If the velocity of the projectile $\left(\mathrm{V}_{\text {pro }}\right)$ is known, the equation can be solved. One of the two roots gives a negative Mach number which can be discarded. 


$$
M=\frac{(\gamma+1)}{4} \frac{V_{\text {pro }}}{a_{\mathrm{atm}}}+\sqrt{\left(\frac{(\gamma+1)}{4} \frac{V_{\text {pro }}}{a_{\mathrm{atm}}}\right)^{2}+1}
$$
Using the normal shock waves equations for the pressure ratio and substituting equation
2.5 for the Mach number you get

$$
\frac{P_{1}}{P_{a t m}}=\frac{2 \gamma}{(\gamma+1)}\left[\frac{(\gamma+1)}{4} \frac{V_{\text {pro }}}{a_{a t m}}+\sqrt{\left(\frac{(\gamma+1)}{4} \frac{V_{p r o}}{a_{a t m}}\right)^{2}+1}\right]^{2}-\frac{(\gamma-1)}{(\gamma+1)}
$$

which is the relationship between the pressure increase in front of the projectile with respect to the projectile velocity $\left(V_{\text {pro }}\right)$ itself. During the computation, the pressure $P_{1}$ is determined using the projectile velocity from the previous time step.

For a projectile velocity in the range of $1800 \mathrm{~m} / \mathrm{s}$, the pressure ratio $\mathrm{P}_{1} / \mathrm{P}_{\text {atm }}$ can reach a value of about 50. Starting with an initial pressure of one atmosphere, the pressure in front of the projectile can go as high as $5 \mathrm{MPa}$ which is about $10 \%$ of the projectile

\subsection{Gun Section/Driver Section}

As already mentioned in the introduction, the driver section here is considered to have uniform conditions along its whole length. It is equivalent as saying that the speed of sound in the driver section is infinite. The other approximation we are going to make is that the driver gas velocity in the driver section $\left(\mathrm{u}_{4}\right)$ is much smaller than the speed of Sound in that section $\left(a_{4}\right)$ so the first term in the energy equation 2.7 will be neglected. The energy conservation equation between the flow in the driver section and the gun section is presented here only for the case of a perfect gas. In the test cases presented in less than $0.1 \%$. the value of then $5 \%$ the value of $a_{4}$. It means that the first term $\left(u_{4}\right)$ is indices defined in figure 2 . The indices in equation 2.7 refer to

$$
\cdots \quad \therefore \quad \frac{u_{4}{ }^{2}}{2}+\frac{a_{4}{ }^{2}}{(\gamma-1)}=\frac{u_{3}{ }^{2}}{2}+\frac{a_{3}{ }^{2}}{(\gamma-1)}
$$

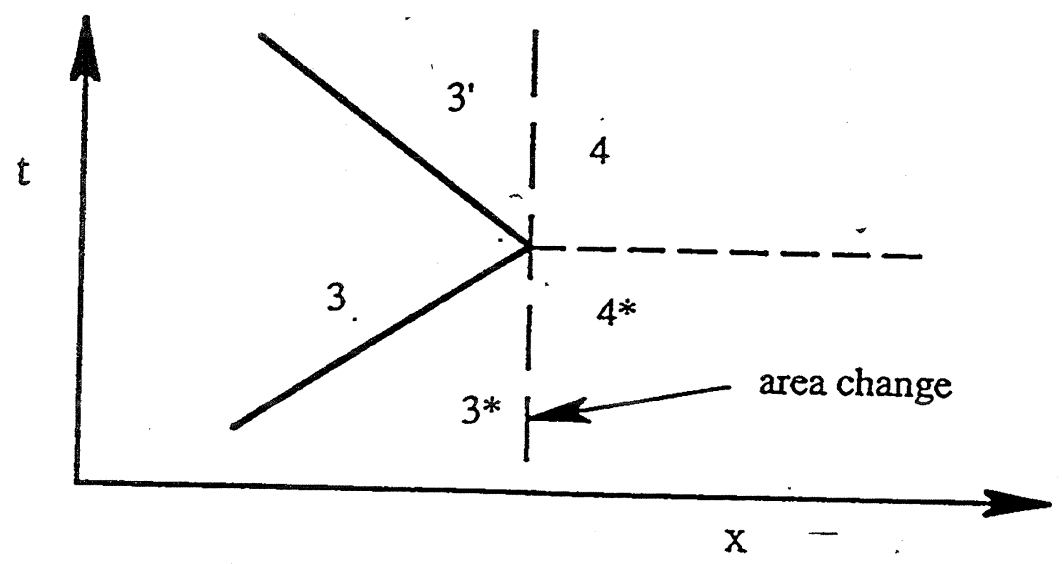

Figure 2.1 Characteristic lines with an area change. 
An additional equation comes from the characteristic method applied between the flow conditions 3 and $3^{\prime}$. It gives equation 2.8 where the conditions in regions 3 are known. The problem is then reduced to 3 unknowns, a4, u $3^{\prime}$, and $a_{3}$ and two equations.

$$
u_{3}-\frac{2}{\gamma-1} a_{3}=u_{3:}-\frac{2}{\gamma-1} a_{3}
$$

The third equation will come from the conservation of mass. It is possible to compute the amount of gas that has left the driver section since the last characteristic wave hit the area change (equation 2.9)

$$
\Delta T_{\text {mass }}=A_{\text {pro }} \rho_{3} * u_{3} * \Delta t
$$

The indices $3 *$ here represent the conditions at the area change the last time a characteristic wave was there and $\Delta t$ is the time elapsed since. At the same time, because of the piston motion, the volume of the driver section will change. It can be written

$$
\Delta\left(\mathrm{Vol}_{4}\right)=\mathrm{A}_{\mathrm{pis}}\left(\mathrm{X}_{\mathrm{pis}}-\mathrm{X}^{*} \text { pis }\right)
$$

where $X^{*}$ pis and $X_{\text {pis }}$ are respectively the position of the piston at the previous time step and the present one. The method used to determine the piston trajectory will be presented in section 2.3 .

Using here again the notation $4 *$ for the conditions in region 4 the last time a characteristic wave hit the area change, we can write

$$
\therefore \quad \therefore-\rho_{4}=\frac{T_{\text {mass }}^{*}-\Delta T_{\text {mass }}}{\mathrm{Vol}_{4}^{*}-\Delta \mathrm{Vol}_{4}}
$$

and because the flow can be considered isentropic

$$
\therefore \quad\left(\frac{\rho_{4}}{\rho_{4^{*}}}\right)^{\frac{\gamma-1}{2}}
$$

It is possible then to determine the three unknowns using equations $2.3,2.4$, and 2.12 . The strength of the minus characteristic in region $3 \mathrm{can}$ also be determined and the computation can go on. Using the isentropic relations, $\mathrm{P}_{4}$ and $\mathrm{T}_{4}$ can also be determined.

\subsection{Piston trajectory}

The motion of the piston is represented by equation 2.13 , which is once again very similar to equation 1.11 presented in section 1.2. The equation has been simplified because in the present case the pressure in region 4 is at least one order of magnitude larger then the pressure in region 7.

$$
M_{\text {pis }} \frac{d V_{\text {pis }}}{d t}=\bar{A}_{\text {pis }}\left[P_{7}-P_{4}\left(1+f_{f}\right)\right]
$$

In the numerical code, $\mathrm{dt}$ is taken as the time elapse since the last time a characteristic reached the area change between section 3 and 4 . The pressure $\mathrm{P}_{4}$ used is the pressure computed at the end of the previous time step (see section 2.2). $\mathrm{P}_{7}$ is determined using the simple expansion wave equation 2.14 , 


$$
\frac{P_{7}}{P_{\text {ini }}}=\left(1-\frac{(\gamma-1)}{2} \frac{V_{\text {pis }}}{a_{\text {ini }}}\right)^{2 \gamma /(\gamma-1)}
$$

where the subscript -ini- represent the initial conditions of the compressed air before the piston launch. This equation is exact as long as the compressed air section is long enough section.

At this point in the development of the light-gas gun it is too early. to say how the compressed air section is going to be designed. Modifications to the software may be necessary if a shorter but larger diameter section is used. Past experience with such design differences between T5 at Caltech and HEG in Germany have shown that these
differences only change the test conditions by around $5 \%$. 